Please do not remove this page

RMIT

UNIVERSITY

\title{
High-performance field effect transistors using electronic Inks of 2D molybdenum oxide nanoflakes
}

Alsaif, Manal M Y A; Chrimes, Adam; Daeneke, Torben; Balendhran, Sivacarendran; Bellisario, Darin; Son, Youngwoo; Field, Matthew

https://researchrepository.rmit.edu.au/esploro/outputs/9921862875001341/filesAndLinks?institution=61RMIT_INST\&index=null

Alsaif, M. M. Y. A., Chrimes, A., Daeneke, T., Balendhran, S., Bellisario, D., Son, Y., Field, M., Zhang, W., Nili Ahmadabadi, H., Nguyen, E., Latham, K., Van Embden, J., Strano, M., Ou, J., \& Kalantar Zadeh, K. (2016). High-performance field effect transistors using electronic Inks of 2D molybdenum oxide nanoflakes. Advanced Functional Materials, 26(1), 91-100. https://doi.org/10.1002/adfm.201503698 Document Version: Accepted Manuscript

Published Version: https://doi.org/10.1002/adfm.201503698 
Thank you for downloading this document from the RMIT Research Repository.

The RMIT Research Repository is an open access database showcasing the research outputs of RMIT University researchers.

RMIT Research Repository: http://researchbank.rmit.edu.aul

\author{
Citation: \\ Alsaif, M, Chrimes, A, Daeneke, T, Balendhran, S, Bellisario, D, Son, Y, Field, M, \\ Zhang, W, Nili Ahmadabadi, H, Nguyen, E, Latham, K, Van Embden, J, Strano, M, \\ Ou, J and Kalantar Zadeh, K 2016, 'High-performance field effect transistors using \\ electronic Inks of 2D molybdenum oxide nanoflakes', Advanced Functional \\ Materials, vol. 26, no. 1, pp. 91-100.
}

See this record in the RMIT Research Repository at:

https://researchbank.rmit.edu.au/view/rmit:35747

Version: Accepted Manuscript

Copyright Statement:

(c) 2015 WILEY-VCH Verlag GmbH \& Co. KGaA, Weinheim

Link to Published Version:

http://dx.doi.org/10.1002/adfm.201503698 
DOI: $10.1002 /$ ((please add manuscript number))

Article type: Full Paper

\section{High Performance Field Effect Transistors using Electronic Inks of Two-Dimensional Molybdenum Oxide Nanoflakes}

Manal M. Y. A. Alsaif,* Adam F. Chrimes, Torben Daeneke, Sivacarendran Balendhran, Darin O. Bellisario, Youngwoo Son, Matthew R. Field, Wei Zhang, Hussein Nili, Emily P. Nguyen, Kay Latham, Joel van Embden, Michael S. Strano, Jian Zhen Ou, * and Kourosh Kalantar-zadeh*

Miss. M. M. Y. A. Alsaif, Dr. T. Daeneke A. F. Chrimes, Dr. T. Daeneke, Mr. W. Zhang, Miss. Emily P. Nguyen, Dr. J. Z. Ou, Prof. K. Kalantar-zadeh

School of Electrical and Computer Engineering, RMIT University, Melbourne, Victoria 3001, Australia

E-mail: s3372431@student.rmit.edu.au

E-mail: jianzhen.ou@rmit.edu.au

E-mail: kourosh.kalantar@rmit.edu.au

Dr. S. Balendhran, Mr. H. Nili

Functional Materials and Microsystems Research Group, RMIT University, Melbourne, Victoria 3001, Australia

Mr. D. O. Bellisario, Mr. Y. Son, Prof. M. S. Strano

Department of Chemical Engineering, Massachusetts Institute of Technology, Cambridge, Massachusetts 02139 United States

Dr. M. R. Field

RMIT Microscopy and Microanalysis Facility, RMIT University, Melbourne, Australia

Prof. K. Latham

School of Applied Sciences, RMIT University, Melbourne VIC 3001, Australia

Dr. J. V. Embden

CSIRO Manufacturing Flagship, Bayview Avenue, Clayton, Victoria 3168, Australia

Keywords: two-dimensional, molybdenum oxide, liquid phase exfoliation, field effect transistors, solar light 
Planar two-dimensional (2D) materials are possibly the ideal channel candidates for future field effect transistors (FETs), due to their unique electronic properties. However, the performance of FETs based on 2D materials is yet to exceed those of conventional silicon based devices. Here we present a $2 \mathrm{D}$ channel thin film made from liquid phase exfoliated molybdenum oxide nanoflake inks with highly controllable sub-stoichiometric levels. The ability to induce oxygen vacancies by solar light irradiation in an aqueous environment allows the tuning of electronic properties in 2D sub-stoichiometric molybdenum oxides $\left(\mathrm{MoO}_{3-x}\right)$. The highest mobility is found to be $\sim 600 \mathrm{~cm}^{2} \mathrm{~V}^{-1} \mathrm{~s}^{-1}$ with an estimated free electron concentration of $\sim 1.6 \times 10^{21} \mathrm{~cm}^{-3}$ and an optimal $I_{O n} / I_{O f f}$ ratio of $>10^{5}$ for the FETs made of $2 D$ flakes irradiated for $30 \mathrm{~min}(x=0.042)$. These values are significant and represent a real opportunity to realize the next generation of tunable electronic devices using electronic inks.

\section{Introduction}

The emergence of two-dimensional (2D) semiconductors, which are made of single or few layers of crystal unit cell thickness components, has led to a range of unique chemical and physical properties that don't exist in their bulk counterparts. ${ }^{[1-4]}$ In particular, the quantum well effect together with in-plane free charge transport are features that make the 2D semiconductors attractive as channel materials for field effect transistors (FETs). ${ }^{[2-5]}$

Semiconducting members of the transition metal dichalcogenide (TMD) family is now form a widely studied category of 2D materials. For developing FETs, a typical representative is 2D molybdenum disulphide $\left(\mathrm{MoS}_{2}\right)$ with reported mobilities in the range of 10 to $1,000 \mathrm{~cm}^{2} \mathrm{~V}^{-1} \mathrm{~s}^{-1}$ and as exfoliated carrier concentration of $\sim 10^{19} \mathrm{~cm}^{-3}$ in a single layer. ${ }^{[3,6-8]}$ Other few-layered TMDs such as molybdenum diselenide $\left(\mathrm{MoSe}_{2} ; \sim 10^{19} \mathrm{~cm}^{-3}\right)$, tungsten disulphide $\left(\mathrm{WS}_{2} ; \sim 10^{16} \mathrm{~cm}^{-3}\right)$ and tungsten diselenide $\left(\mathrm{WSe}_{2} ; \sim 10^{18} \mathrm{~cm}^{-3}\right.$ ) have charge 
mobilities that likewise reach a few hundred $\mathrm{cm}^{2} \mathrm{~V}^{-1} \mathrm{~s}^{-1} \cdot{ }^{[6,9,10]}$ These numbers are still not competitive with reference to those of conventional silicon based devices. ${ }^{[5,11]}$ There are a few issues that currently affect the potentials of FETs based on TMDs. In order to develop high transconductance FETs in general, the drain and source electrode contacts should show the smallest barrier for the exchange of free carriers, ${ }^{[12]}$ ENREF_12 and the free carrier concentrations should be increased. Doping TMDs is known to produce enhanced carrier concentrations of $6 \times 10^{18}, 2.5 \times 10^{19}$ and $10^{20} \mathrm{~cm}^{-3}$ for few-layer $\mathrm{WS}_{2}, \mathrm{WSe}_{2}$ and $\mathrm{MoS}_{2}$, respectively. ${ }^{[12,13]}$ Such concentrations can make the electrode contacts more ohmic. However, their mobility still remains subdued. The free carrier mobilities in TMDs are limited by the Coulomb scattering effect given TMDs small relative dielectric constants $(\kappa) .{ }^{[14]}$ The mobility is even more degraded in highly doped TMDs_ENREF_23. ${ }^{[12,13]}$

Semiconducting 2D transition metal oxides (TMOs) have attracted less attention compared to 2D TMDs due to their generally wider band-gap energies and low carrier concentrations in their stoichiometric states. ${ }^{[15]}$ However, selected TMOs have some remarkable properties that can benefit FETs such as a large $\kappa$, which reduces the Coulomb scattering effect, while providing the possibility to accommodate ionic dopants to manipulate the material's electronic properties. ${ }^{[14,15]}$ Molybdenum trioxide $\left(\mathrm{MoO}_{3}\right)$, a member of the TMO family, is a chemically stable $n$-type semiconductor with a high dielectric constant. ${ }^{[14-16]}$ It is well known that the $\alpha-\mathrm{MoO}_{3}$ crystal phase has a layered structure. Furthermore, its electronic bandgap can be manipulated by ionic intercalation processes (commonly hydrogen and alkali metal ions). In particular, hydrogen ion $\left(\mathrm{H}^{+}\right)$intercalation has been well studied in $\alpha-\mathrm{MoO}_{3}$ and allow to tune the material's physicochemical properties, leading to intercalated $\mathrm{MoO}_{3}$ compounds and eventually sub-stoichiometric molybdenum oxides $\left(\mathrm{MoO}_{3-x}\right){ }^{[15]}$ The family of $\mathrm{MoO}_{3-x}$ normally includes molybdenum oxides with sub-stoichiometric levels $(x)$ in the range of $0<x<1$. Most compounds of $\mathrm{MoO}_{3-x}(0<x \leq 0.125)$ such as $\mathrm{Mo}_{9} \mathrm{O}_{26}$ and $\mathrm{Mo}_{8} \mathrm{O}_{23}$ show 
semiconducting behaviour, while other phases with higher $x(0.125 \leq x<1)$, such as $\mathrm{Mo}_{4} \mathrm{O}_{11}$, are quasi-metallic. ${ }^{[17]}$ When $x=1$, it forms a thermodynamically stable semiconducting compound $\left(\mathrm{MoO}_{2}\right)$ of reduced bandgap. ${ }^{[18,19]}$ Single sub-stoichiometric oxide flakes have been incorporated in 2D FETs. ${ }^{[14]}$ Despite the fact that reduced molybdenum oxides demonstrate mobilities exceeding $1,000 \mathrm{~cm}^{2} \mathrm{~V}^{-1} \mathrm{~s}^{-1}$ their $\mathrm{I}_{\mathrm{On}} / \mathrm{I}_{\mathrm{Off}}$ ratios are poor as there is still no report on the optimum oxygen vacancies required to obtain the most efficient FET operation. $^{[14]}$

In addition to developing FETs using single 2D flakes, establishing high performance FETs using thin films based on 2D flake stacks is an important challenge. ${ }^{[20]}$ Such films are generally made using so called "electronic ink", which in our case are suspensions of 2D flakes, that can be deposited onto substrates using a variety of techniques, including printing, drop-casting and templating. ${ }^{[20]}$ Such films can be used in flexible electronics, touch screens, sensors, RFID tags, photovoltaic cells, and electronic textiles. ${ }^{[2,21,22]}$ Some of the best reports on thin film based FETs that incorporate graphene flakes only reach mobilities near $100 \mathrm{~cm}^{2} \mathrm{~V}^{-1} \mathrm{~s}^{-1}$ with poor $\mathrm{I}_{\mathrm{On}} / \mathrm{I}_{\mathrm{Off}}$ ratios. ${ }^{[21]}$ There are also recent reports on incorporating thin films of $2 \mathrm{D} \mathrm{WS}$ flakes. ${ }^{[22]}$ However, although the reported mobilities are high, the $\mathrm{I}_{\mathrm{On}} / \mathrm{I}_{\mathrm{Off}}$ ratios were too low for establishing FETs.

Here we produce electronic inks of $2 \mathrm{D} \mathrm{MoO}_{3-x}$ flakes and use them for developing channels for FETs with extraordinary abilities. We use a solar light irradiation based method to control the oxygen vacancies and free electron concentrations $(N)$ in liquid-phase exfoliated (LPE) 2D $\mathrm{MoO}_{3-x}$ flakes. Through the controlled manipulation of $x$, we show that the carrier concentrations, energy band edges, and carrier charge mobilities in 2D $\mathrm{MoO}_{3-x}$ based FETs can be tuned. Furthermore, these parameters are evaluated as a function of the 2D flakes' stoichiometry. Finally, we present tunable FETs based on 2D $\mathrm{MoO}_{3-\mathrm{x}}$ nanoflakes with 
different sub-stoichiometric levels and demonstrate the optimal sub-stoichiometric value using LPE technique which the maximum transconductance is obtained.

\section{Results and Discussion}

\subsection{Characterization of 2D Molybdenum Oxide Flakes}

Suspensions of 2D molybdenum oxide flakes were prepared in an ethanol/water $(50 \% \mathrm{v} / \mathrm{v})$ mixture to form the electronic inks, as described in the Experimental Section. Samples of equal volume and concentration were irradiated by a solar simulator for $5 \mathrm{~min}, 10 \mathrm{~min}, 20$ min, $30 \mathrm{~min}, 1 \mathrm{~h}, 2 \mathrm{~h}$ and $5 \mathrm{~h}$ to obtain the sub-stoichiometric $2 \mathrm{D} \mathrm{MoO}_{3-x}$ flake suspensions.

Figure 1a shows the schematic crystal structure of pristine $\alpha-\mathrm{MoO}_{3}$, wherein each molybdenum atom bonds to edge-sharing, corner-sharing and unshared terminal oxygen atoms. ${ }^{[23]}$ The ionization energy (IE) of the pristine (initial) sample of $\mathrm{MoO}_{3}$ was measured by photoelectron spectroscopy in air (PESA), which correlates to the valence band maximum $(\mathrm{VBM})$ and was found to be $-5.58 \mathrm{eV}$ with respect to vacuum $(\mathrm{vac}),{ }^{[24]}$ which is below the water oxidation potential $\left(\mathrm{H}_{2} \mathrm{O} / \mathrm{O}_{2} \sim-5.3 \mathrm{eV}\right.$ respect to vac $)$ in our solar light induced reaction conditions (see Supporting Information Note 1 and Figure S1). As such, the photoexcited electrons remain in the conduction band $(\mathrm{CB})$ and $\mathrm{H}^{+}$ions are intercalated into $2 \mathrm{D} \alpha$ $\mathrm{MoO}_{3}{ }^{[19,25]}$ The electrons in the $\mathrm{CB}$ are strong reductants, providing the driving force for the intercalation reaction within the $\mathrm{MoO}_{3}$ structure (conduction band minimum $(\mathrm{CBM})=-2.73$ $\mathrm{eV}$ with respect to $v a c)$._ENREF $32^{[19,24,25]}$ The intercalated $\mathrm{H}^{+}$ions are mostly bonded to edge-shared oxygen and terminal oxygen atoms, which forms $\mathrm{OH}_{2}$ groups; hence transforming 2D $\mathrm{MoO}_{3}$ into $2 \mathrm{D} \mathrm{H}_{x} \mathrm{MoO}_{3}$ (Figure 1b). ${ }^{[19,23]}$ This causes the increase of interlayer spacing. ${ }^{[26]}$ However, the $\mathrm{OH}_{2}$ groups are not stable in the presence of environmental perturbations (e.g. heat) and are eventually released from their original positions in the crystal 
lattice, leaving alone oxygen vacancies and subsequently forming sub-stoichiometric 2D $\mathrm{MoO}_{3-x}{ }^{[23]}$ This rapid process of defect formation also causes crystal deformation and cracking in both intra-layer and inter-layer directions, hence reducing the lateral dimensions and thickness of the flakes. ${ }^{[26]}$ The average lateral dimensions of molybdenum oxide flakes before and after solar light illumination for different durations were investigated using dynamic light scattering (DLS) (Figure 1c and Figure S2 in the Supporting Information). The average lateral dimension of the initial $\mathrm{MoO}_{3}$ flakes is $\sim 170 \mathrm{~nm}$, while after 5 min irradiation it is reduced by approximately $10 \%$. Interestingly at $30 \mathrm{~min}$ irradiation duration, the average lateral dimension of flakes falls to $\sim 130 \mathrm{~nm}$. The dynamics of the lateral dimension reduction changes after $30 \mathrm{~min}$ of irradiation and the average value reaches $\sim 80 \mathrm{~nm}$ at the $5 \mathrm{~h}$ mark. Transmission electron microscopy (TEM) verifies that the lateral dimensions of 2D flakes after $5 \mathrm{~h}$ irradiation are distinctly reduced (Figure 1d,e and Figure S3 in the Supporting Information). The thicknesses of the nanoflakes before and after $5 \mathrm{~h}$ irradiation were also assessed using atomic force microscopy (AFM). Figure 1f,g show that the $2 \mathrm{D}$ morphologies of the flakes are retained regardless of the light irradiation duration. The initial average flake thickness is made of around 5 monolayers, while they are reduced to an average of 3 monolayers after the $5 \mathrm{~h}$ irradiation (Figure S4 in the Supporting Information). As such, exfoliation continues during the whole solar irradiation process.

The initial 2D molybdenum oxide nanoflakes are made of crystalline orthorhombic $\alpha-\mathrm{MoO}_{3}$ according to the X-ray diffraction (XRD) pattern (Figure S5, Supporting Information). Figure 2a shows a high resolution TEM (HRTEM) image highlighting the lattice fringes of the 2D nanoflakes. A spacing of $0.39 \mathrm{~nm}$ is observed associated with the $\left(\begin{array}{lll}1 & 0 & 0\end{array}\right)$ plane of $\alpha-\mathrm{MoO}_{3}$. The corresponding selected area electron diffraction (SAED) pattern (Figure 2b) clearly distinguishes diffraction spots representing the $\left(\begin{array}{lll}2 & 0 & 0\end{array}\right)$ and $\left(\begin{array}{lll}0 & 0 & 2\end{array}\right)$ planes of $\alpha-\mathrm{MoO}_{3}{ }^{[19,27]}$ However after_ENREF_215 h solar light exposure, _ENREF_35some of the lattice fringes 
appear disordered as a consequence of $\mathrm{H}^{+}$intercalation (Figure 2c). This disorder is confirmed from the polycrystalline ring SAED pattern (Figure 2d). The intercalation of the $\mathrm{H}^{+}$ions into the crystal lattice eventually produces cracks and splits the crystal into smaller sizes. ${ }^{[28]}$

To investigate the evolution of this intercalation process, Raman spectra of 2D molybdenum oxide for different solar illumination durations were obtained (Figure 3a). Strong Raman peaks are observed for the initial sample which are associated to $\alpha-\mathrm{MoO}_{3}$ (see Supporting Information Note 2 for further discussion). ${ }^{[19,23]}$ ENREF 32 New peaks appear after 30 min of solar light exposure, which can be assigned to $\mathrm{MoO}_{3-x}$, suggesting the appearance of oxygen vacancies. ${ }^{[29]}$ X-ray photoelectron spectroscopy (XPS) was used for identifying the sub-stoichiometry of the 2D flakes (Figure $3 b$ ). The doublets at 235.98 and $232.68 \mathrm{eV}$ are attributed to the binding energies of the $3 d_{3 / 2}$ and the $3 d_{5 / 2}$ orbital electrons of Mo $^{6+}$, respectively. ${ }^{[19]}$ The integrated areas of the two doublets are in a 2:3 ratio and the energy split between them is $3.1 \mathrm{eV}$, in agreement with $\alpha-\mathrm{MoO}_{3}{ }^{[15]}$ Two peaks centered at 234.58 and $231.28 \mathrm{eV}$ appear in the Mo $3 \mathrm{~d}$ core level spectrum after 5 min of solar light irradiation. These peaks are at lower binding energies compared to $\mathrm{Mo}^{6+}$, indicating the appearance of the $\mathrm{Mo}^{5+}$ oxidation state within the flakes. The intensities of these $\mathrm{Mo}^{5+}$ peaks, which are correlated with the sub-stoichiometry of molybdenum oxide flakes, increase with the irradiation duration. ${ }^{[19]}$ The sub-stoichiometric level in 2D molybdenum oxide flakes prepared here is lower than reported in our previous work in which an acetonitrile solvent was used. ${ }^{[19]}$ This may be due to the fact that acetonitrile has a higher dispersion solubility parameter $\left(\delta_{\mathrm{d}}\right.$ $=64.3$ and a surface tension of $27.6 \mathrm{mN} / \mathrm{m})$ than ethanol $\left(\delta_{\mathrm{d}}=60.4\right.$ and surface tension of $22 \mathrm{mN} / \mathrm{m}),{ }^{[30]}$ facilitating the exfoliation process and producing surface areas for the intercalation process. $^{[31]}$

During the formation of an oxygen vacancy in the crystal structure upon light exposure, the $\mathrm{Mo}^{6+}$ neighbouring the oxygen vacancy in the $\mathrm{MoO}_{3}$ lattice is reduced to $\mathrm{Mo}^{5+}$, injecting an 
electron to the $\mathrm{CB} \cdot{ }^{[14,23]}$ This injected electron is delocalized within the layers and acts as a Drude-model-like free electron, ${ }^{[14]}$ hence modulating the electronic band structure of the 2D flakes. ${ }^{[14]}$ The $N$ per unit volume $\left(\mathrm{cm}^{-3}\right)$ of electrons for different light irradiation durations is estimated from the $\mathrm{Mo}^{5+} / \mathrm{Mo}^{6+}$ area ratio in $\mathrm{MoO}_{3-x}$ extracted from the XPS measurements (Table 1a and Figure S6 in the Supporting Information). It is found that $N$ and oxygen vacancies both increase with the solar light duration. This increase in $N$ shifts the Fermi energy level $\left(E_{F}\right)$ upward towards the $\mathrm{CB}$ (Figure 3c and Table S1 in the Supporting Information). ${ }^{[32]}$ It is important to note that by introducing oxygen vacancies a new occupied state appears within the $E_{g}$ of $\mathrm{MoO}_{3-x}$, labeled $d$ in Figure 3d_ENREF_45. This defect state arise because an $\mathrm{O}^{2-}$ ion is removed from the valence-band spectra of $\mathrm{MoO}_{3-x \cdot}{ }^{[33]}$ The previously empty $4 \mathrm{~d}$ band of $\mathrm{MoO}_{3}$ becomes partially occupied with electrons, giving rise to the defect band seen close to the $E_{F}\left(1.28 \mathrm{eV}\right.$ below $\left.E_{F}\right)$ which is enhanced in the intensity by increasing the solar light duration (Figure $3 d$ ). ${ }^{[33]}$

Prolonging the solar irradiation of the flakes moves their valence band (VB) (Table S1, Supporting Information) closer to that of the work function of gold, which forms the FET drain and source electrodes_ENREF_45. Molybdenum oxide is a well-known hole extracting material that can exchange electrons at its $\mathrm{VB},{ }^{[24,34]}$ coinciding gold's $E_{F}$ that makes a small barrier contact_ENREF_34_ENREF_44. The enhancement in the electron concentration and tuning of the VB modify the system to obtain the optimal $\mathrm{I}_{\mathrm{On}} / \mathrm{I}_{\mathrm{Off}}$ ratio for FETs made of $2 \mathrm{D}$ $\mathrm{MoO}_{3-x}$ flakes at $x=0.042$ (30 min irradiation), which will be discussed later. Interestingly, the estimated $E_{g}$ of $\mathrm{MoO}_{3-x}$ for samples of $x=0.042$ and $x=0.125$ (5 h irradiation) are 2.74 and $2.82 \mathrm{eV}$, respectively (Figure S9a,b, Supporting Information). Thus, the CBM for both of these samples were evaluated to be $\sim 2.60$ and $2.56 \mathrm{eV}$, respectively (Figure S9a,b, Supporting Information). The $E_{F}$ of both the initial and solar light exposed flakes never exceeds the CBM and thus the highly-doped flakes should still remain semiconducting. 


\subsection{Fabrication and Characterization of FETs based on 2D Molybdenum Oxide Flakes}

Figure 4a-c show a schematic highlighting the fabrication process of FETs using inks of 2D molybdenum oxide flakes. Details are presented in the Experimental Section. From the examples shown in Figure 4d,e, the drop-casted thin films all have smooth surfaces and are formed by horizontally interconnected 2D molybdenum oxide flakes. Within the FET channels, the 2D nanoflakes are horizontally re-stacked on the top of each other as evidenced by both cross-sectional scanning electron microscopy (SEM) and scanning probe microscopy (SPM). These data confirm that the FET channels are made of true 2D components.

We characterized the FETs using a semiconductor parameter analyzer and shielded probe station at room temperature. A back gate voltage was applied to the silicon substrate and the two electrodes act as drain and source terminals (Figure 4c). The I-V curves of the FETs based on 2D molybdenum oxide flakes of different $x$ are illustrated in Figure S10 in the Supporting Information. The drain-source current $\left(\mathrm{I}_{\mathrm{SD}}\right) v s$. applied gate voltage $\left(\mathrm{V}_{\mathrm{G}}\right)$ from -1 to $1 \mathrm{~V}$ are extracted from Figure S10 in the Supporting Information and presented in Figure 5a. For all devices, their $\mathrm{I}_{\mathrm{SD}}$ are enhanced with the increase of the applied gate voltages. They are typical characteristics of channel FETs and confirm the semiconducting character of the 2D molybdenum oxide flakes regardless of their $x$ values._ENREF $53^{[14]}$ It is found that $\mathrm{I}_{\mathrm{SD}}$ enhances when $x$ increases from 0.025 to 0.042 . However, for the FET devices made of flakes with $x>0.063$ the $\mathrm{I}_{\mathrm{SD}}$ dramatically decrease and eventually drop much below the initial value at $x=0.125$.

Figure $5 b$ shows the $\mathrm{I}_{\mathrm{On}} / \mathrm{I}_{\mathrm{Off}}$ ratio as a function of $x$. The highest $\mathrm{I}_{\mathrm{On}} / \mathrm{I}_{\mathrm{Off}}$ ratio is $\sim 3.0 \times 10^{5}$ for FETs made of flakes of $x=0.042$. However, the ratio is significantly reduced to $\sim 1.2 \times 10^{2}$ at $x=0.125$ (Table $1 \mathrm{~b}$ ). As previously discussed, a combination of the optimum barrier contact 
and electron concentration contributes to the optimum $\mathrm{I}_{\mathrm{On}} / \mathrm{I}_{\mathrm{Off}}$ ratio of the FETs made of $2 \mathrm{D}$ flakes with $x=0.042$. Considering that an $\mathrm{I}_{\mathrm{On}} / \mathrm{I}_{\mathrm{Off}}$ ratios greater than $10^{4}$ are acceptable for establishing functional FETs, ${ }^{[1]}$ here, the obtained ratios for many of the $x$ values are industrially plausible. The introduction of the oxygen vacancies produces a defect state nearly $1.28 \mathrm{eV}$ below the $E_{F}$. Given the heavy doping of the materials, they may behave like degenerate semiconductors with the $E_{F}$ very close to the CBM. In such a case, we may view the system as possessing a small quasi-bandgap that can be readily turned off at low gate voltages. This can also be another reason that contributes to the large $\mathrm{I}_{\mathrm{On}} / \mathrm{I}_{\mathrm{Off}}$ ratio of the optimum semiconducting effect obtained at $x=0.042$. The transconductance $\left(g_{m}\right)$ of the FETs at $\mathrm{V}_{\mathrm{SD}}=100 \mathrm{mV}$ is extracted and calculated from their I-V characteristics using: ${ }^{[35]}$

$$
g_{m}=\mathrm{dI}_{\mathrm{SD}} / \mathrm{dV}_{\mathrm{G}}
$$

The corresponding carrier field effect mobilities $\left(\mu_{\mathrm{FE}}\right)$ are determined using (3) and shown in Table 1b:

$$
\mu_{F E}=\frac{L}{W C_{i} \mathrm{~V}_{\mathrm{SD}}} \times g_{m}
$$

where $L$ and $W$ are the channel length and width, respectively. $C_{i}$ is $1.91 \times 10^{-8} \mathrm{~F} \mathrm{~cm}^{-2}$ which is the capacitance per unit area between the channel and the back gate. ${ }^{[7]}$ The calculated $g_{m}$ and the measured $\mu_{\mathrm{FE}}$ are presented in Figure 5c,d and Table $1 \mathrm{~b}$. The highest value of $g_{m}$ and $\mu_{\mathrm{FE}}$ were $\sim 3.45 \mu \mathrm{S}$ and $\sim 600 \mathrm{~cm}^{2} \mathrm{~V}^{-1} \mathrm{~s}^{-1}$, respectively, for the device of $x=0.042(30 \mathrm{~min}$ irradiation), while the device of $x=0.125$ ( $5 \mathrm{~h}$ irradiation) had the lowest $g_{m}$ of $\sim 0.143 \mu \mathrm{S}$ and $\mu_{\mathrm{FE}}$ of $\sim 25 \mathrm{~cm}^{2} \mathrm{~V}^{-1} \mathrm{~s}^{-1}$. Interestingly, the value of $\mu_{\mathrm{FE}}$ for the FETs of $x=0.042$ is significantly higher than the mobility of thin film transistors based on typical mono- or fewlayered TMDs $\left(\sim 10-1,000 \mathrm{~cm}^{2} \mathrm{~V}^{-1} \mathrm{~s}^{-1}\right){ }^{[3,6,8,9,12,36]}$ The optimal $\mu_{\mathrm{FE}}$ that occurs for the device at $x=0.042$ corresponds to $\mathrm{Mo}^{5+/} \mathrm{Mo}^{6+}=0.083$, coinciding orthorhombic to monoclinic phase change, which possibly results in gaining optimal semiconducting properties at this sub- 
stoichiometry. It is worthwhile to define a virtual free carrier mobility per flake by considering the average number of flakes in thickness (from Figure 4 d,e, it is $\sim 95$ layer in a $850 \mathrm{~nm}$ thick channel and $\mathrm{MoO}_{3}$ relative (static) dielectric constant of 35) ${ }^{[14]}$ that is equal to $\sim 6 \mathrm{~cm}^{2} \mathrm{~V}^{-1} \mathrm{~s}^{-1}$ per flake. This value is still a remarkably large, taking into account that the high electron scattering occurs at the flake boundaries.

The $\mu_{\mathrm{FE}}$ of $2 \mathrm{D} \mathrm{MoO}_{3-x}$ flake based FETs was assessed as a function of $N$ (Details are presented in Supporting Information Note 3 and Figure S11 in the Supporting Information). The assessed $\mu_{\mathrm{FE}}$ and the theoretical (Matthiessen's rule) values of carrier field effect mobility $\left(\mu_{\text {Total }}\right)$ are presented in Figure $5 \mathrm{~d}$ and Figure S11 in the Supporting Information. The trend of $\mu_{\mathrm{FE}}$ can be explained by various electron scattering mechanisms. It is found that for $x<0.042$ the main limiting factor for $\mu_{\mathrm{FE}}$ is the ionized charged scattering effect (Coulomb scattering). ${ }^{[37]}$ As discussed in the introduction, $\mathrm{MoO}_{3-x}$ with its large relative (static) dielectric constant screens the Coulomb charges. ${ }^{[14,19]}$ This reduces ionized charge scattering effect and produces remarkable free charge carrier mobility in the FET channels. Subsequently, at $x=0.042$ and $x=0.063$ both ionized charge scattering and acoustic deformation potential scattering become the dominant effects. For the 2D flakes with $x>0.063$, optical phonon scattering becomes the governing effect. ${ }^{[37,38]}$

It is important to emphasize that the $2 \mathrm{D}$ flakes forming the thin films are re-stacked horizontally; potentially helping the planar conduction of free charge carries within the FET channels, hence enhancing the mobility. From Figure $5 \mathrm{~d}$, we see that the measured $\mu_{\mathrm{FE}}$ is still almost an order of magnitude smaller than the calculated $\mu_{\text {Total }}$, which may be the result of significant grain boundary scattering $\left(\mu_{\mathrm{GB}}\right)$ existing between the interconnected flakes given their relatively small lateral dimensions $(\sim 100-200 \mathrm{~nm}) .{ }^{[39]}$ Moreover, the decrease in $\mu_{\mathrm{FE}}$ for $x>0.063$ is much larger than the calculated trend, implying an increased effect of $\mu_{\mathrm{GB}}$ as the flake sizes are dramatically reduced to below $100 \mathrm{~nm}$. It is also possible that more defects, 
which act as charge traps, are formed when $2 \mathrm{D} \mathrm{MoO}_{3-x}$ flakes become highly substoichiometric. ${ }^{[40]}$

\section{Conclusion}

We developed electronic inks based on 2 $\mathrm{D} \mathrm{MoO}_{3-x}$ nanoflakes obtained by a LPE method, for which the sub-stoichiometric and Fermi levels as well as free electron concentrations could be manipulated in a highly controllable manner by varying the light irradiation duration. FETs were fabricated using these inks by a drop-casting process, forming films made of layers of horizontally re-stacked 2D flakes. By investigating the performances of our FETs as a function of $x$ under different solar irradiation time, we found that the device irradiated within $30 \min (x=0.042)$ reached the highest charge carrier mobility of $\sim 600 \mathrm{~cm}^{2} \mathrm{~V}^{-1} \mathrm{~s}^{-1}$ with an $\mathrm{I}_{\mathrm{On}} / \mathrm{I}_{\mathrm{Off}}$ ratio of $\sim 3.0 \times 10^{5}$. We demonstrated that a gap state appears in the bandgap of $\mathrm{MoO}_{3-x}$, which contributed to the semiconducting behavior of the flakes. The horizontal re-stacking of the flakes and the confinement of the electric field lines by a high dielectric medium of $\mathrm{MoO}_{3-}$ $x$ also contributed to the high free carrier charge mobility.

Given the scalability and reliability of the LPE technique and the ease of irradiation process for tuning the material, the electronic ink of $2 \mathrm{D} \mathrm{MoO}_{3-x}$ flakes is promising for future ultrahigh performance printed nanoelectronic and optoelectronic devices. 


\section{Experimental Section}

2D molybdenum oxide flakes synthesis and FET device fabrication: $3 \mathrm{~g}$ of $\mathrm{MoO}_{3}$ powder (99\% purity, China Rare Metal Material Co.) was ground with $0.6 \mathrm{~mL}$ ethanol for $30 \mathrm{~min}$. The powder was then dispersed in ethanol/water $(50 \% \mathrm{v} / \mathrm{v})$ mixture $(45 \mathrm{~mL})$, subjected to probe-sonication (Ultrasonic Processor GEX500) for $120 \mathrm{~min}$ at $125 \mathrm{~W}$, and then centrifuged at $6000 \mathrm{rpm}$ for $30 \mathrm{~min}$ at room temperature. To obtain the electronic inks, the supernatant containing high concentrations of $2 \mathrm{D} \mathrm{MoO}_{3}$ flakes was collected and transferred into small containers with $3 \mathrm{~mL}$ volume each. The supernatant samples were irradiated under the solar simulator (Abet Technologies LS-150) at different time intervals of $5 \mathrm{~min}, 10 \mathrm{~min}, 20 \mathrm{~min}, 30$ min, $1 \mathrm{~h}, 2 \mathrm{~h}$ and $5 \mathrm{~h}$ and subsequently drop-casted at the fixed amount of $50 \mu \mathrm{L}$ on substrates for characterization and FET fabrication. Au/Cr $(150 / 50 \mathrm{~nm})$ electrodes were deposited onto clean n-doped silicon wafer substrates with $500 \mathrm{~nm}$ thick $\mathrm{SiO}_{2}$ surface layers using an electron beam evaporation process and subsequently patterned by conventional photolithography. The spacing between the electrodes was set to $50 \mu \mathrm{m}$. A polydimethylsiloxane (PDMS) reservoir was used for the drop-casting process. The drpcasted devices were then annealed at $75{ }^{\circ} \mathrm{C}$ to remove the trapped water and organic molecules between the flakes and kept at room temperature for electrical investigations. The thicknesses of all FET channels were equally set to $\sim 850 \mathrm{~nm}$. The extended Raman spectra of the drop-casted films (Figure S12, Supporting Information) reveal that there was no observable peak appearing beyond $1000 \mathrm{~cm}^{-1}$, which indicates that the organic residue in the films was fully evaporated.

Characterizations and measurements: Electrical characterizations were carried out using an ARS PSF-10-1-4 Cryogenic Probe Station and an Agilent E5270B analyzer at room temperature. Digital Instruments D3100 AFM, FEI Nova NanoSEM and Hysitron TI950 Triboindenter SPM were used for investigating the film surface and cross-sectional morphologies. Raman spectra were obtained using a micro-Raman spectrometer (Renishaw 
InVia microscope) with a 1200 lines per mm blazed grating and a $1 \mathrm{~mW}$ laser excitation source at $514 \mathrm{~nm}$. Acquisitions were carried out for $10 \mathrm{~s}$ with two averages using a $\times 20$ magnification lens. The nanoflake suspensions were diluted and their average lateral dimensions were measured using DLS technique (ALV 5022F spectrometer). The XRD patterns were collected using a Bruker D4 ENDEAVOR with monochromatic $\mathrm{Cu} \mathrm{K} \alpha$ as radiation source $(\lambda=0.154 \mathrm{~nm})$. The XPS was performed on a Thermo scientific K-Alpha instrument equipped with a monochromated aluminium $\mathrm{K}-\alpha$ source $(1486.7 \mathrm{eV})$. A pass energy of $20 \mathrm{eV}$ was selected and the binding energy of the Mo2p peaks was shifted such that the adventitious $\mathrm{C} 1 \mathrm{~s}$ peak was aligned to $284.8 \mathrm{eV}$. The supernatant containing 2D molybdenum oxide flakes were dropped onto $\mathrm{Cu}$ grids for TEM and HRTEM (JEOL 2100F) characterization. The PESA measurements were conducted on drop-casted samples on glass slides and were measured using a Riken Keiki Model AC-2 PESA spectrometer with power setting of $100 \mathrm{nW}$ and a power number of $1 / 3$.

\section{Supporting Information}

Supporting Information is available from the Wiley Online Library or from the author.

\section{Acknowledgements}

The authors would like to acknowledge funding support from the Australian Research Council (ARC) through Discovery Project DP140100170. The authors also would like to acknowledge the facilities, scientific and technical assistances of the Australian Microscopy and Microanalysis Research Facility (AMMRF) at RMIT University, the Micro Nano Research Facility (MNRF) at RMIT University and the Australian Centre for Materials Science and Engineering (CMSE) of the Commonwealth Scientific and Industrial Research Organization (CSIRO), Australia. 
Received: ((will be filled in by the editorial staff))

Revised: ((will be filled in by the editorial staff)) Published online: ((will be filled in by the editorial staff))

[1] G. Fiori, F. Bonaccorso, G. Iannaccone, T. Palacios, D. Neumaier, A. Seabaugh, S. K. Banerjee, L. Colombo, Nat. Nanotechnol. 2014, 9, 768.

[2] D. Akinwande, N. Petrone, J. Hone, Nat. Commun. 2014, 5, 5678.

[3] Q. H. Wang, K. Kalantar-Zadeh, A. Kis, J. N. Coleman, M. S. Strano, Nat. Nanotechnol. 2012, 7, 699.

[4] S. Balendhran, S. Walia, H. Nili, J. Z. Ou, S. Zhuiykov, R. B. Kaner, S. Sriram, M. Bhaskaran, K. Kalantar-zadeh, Adv. Funct. Mater. 2013, 23, 3952.

[5] L. Li, Y. Yu, G. J. Ye, Q. Ge, X. Ou, H. Wu, D. Feng, X. H. Chen, Y. Zhang, Nat. Nanotechnol. 2014, 9, 372.

[6] X. Song, J. Hu, H. Zeng, J. Mater. Chem. C 2013, 1, 2952.

[7] B. Radisavljevic, A. Radenovic, J. Brivio, V. Giacometti, A. Kis, Nat. Nanotechnol. 2011, 6, 147.

[8] D. Lembke, A. Kis, ACS Nano 2012, 6, 10070.

[9] X. Liu, J. Hu, C. Yue, N. Della Fera, Y. Ling, Z. Mao, J. Wei, ACS Nano 2014, 8, 10396.

[10] B. Chamlagain, Q. Li, N. J. Ghimire, H.-J. Chuang, M. M. Perera, H. Tu, Y. Xu, M. Pan, D. Xaio, J. Yan, D. Mandrus, Z. Zhou, ACS Nano 2014, 8, 5079; J. Huang, L. Yang, D. Liu, J. Chen, Q. Fu, Y. Xiong, F. Lin, B. Xiang, Nanoscale 2015, 7, 4193.

[11] F. Schwierz, Nat. Nanotechnol. 2010, 5, 487.

[12] L. Yang, K. Majumdar, H. Liu, Y. Du, H. Wu, M. Hatzistergos, P. Y. Hung, R. Tieckelmann, W. Tsai, C. Hobbs, P. D. Ye, Nano Lett. 2014, 14, 6275. 
[13] H. Fang, M. Tosun, G. Seol, T. C. Chang, K. Takei, J. Guo, A. Javey, Nano Lett. 2013, 13, 1991; H. Fang, S. Chuang, T. C. Chang, K. Takei, T. Takahashi, A. Javey, Nano Lett. 2012, 12, 3788 .

[14] S. Balendhran, J. Deng, J. Z. Ou, S. Walia, J. Scott, J. Tang, K. L. Wang, M. R. Field, S. Russo, S. Zhuiykov, M. S. Strano, N. Medhekar, S. Sriram, M. Bhaskaran, K. Kalantarzadeh, Adv. Mater. 2013, 25, 109.

[15] M. M. Y. A. Alsaif, S. Balendhran, M. R. Field, K. Latham, W. Wlodarski, J. Z. Ou, K. Kalantar-zadeh, Sens. Actuators, B 2014, 192, 196.

[16] M. Zhong, Z. Wei, X. Meng, F. Wu, J. Li, Eur. J. Inorg. Chem. 2014, 3245; M. M. Y. A. Alsaif, M. R. Field, B. J. Murdoch, T. Daeneke, K. Latham, A. F. Chrimes, A. S. Zoolfakar, S. P. Russo, J. Z. Ou, K. Kalantar-zadeh, Nanoscale 2014, 6, 12780.

[17] R. L. Smith, G. S. Rohrer, J. Solid State Chem. 1996, 124, 104; A. Pergament, V. Malinenko, L. Aleshina, E. Kazakova, N. Kuldin, J. Exp. Phys. 2014, 2014, 6; M. Doerr, J. Feller, H. Oppermann, Cryst. Res. Technol. 1996, 31, 231; E. B. Lopes, M. Almeida, J. Dumas, H. Guyot, C. Escribefilippini, J. Phys.: Condens. Matter 1992, 4, L357; E. Canadell, M. H. Whangbo, Inorg. Chem. 1990, 29, 2256; L. Kihlborg, Acta Chem. Scand. 1959, 13, 954.

[18] L. M. S. Alves, S. S. Benaion, C. M. Romanelli, C. A. M. dos Santos, M. S. da Luz, B. S. de Lima, F. S. Oliveira, A. J. S. Machado, E. B. Guedes, M. Abbate, R. J. O. Mossanek, Braz. J. Phys. 2015, 45, 234; F. Zeng, W.-B. Zhang, B.-Y. Tang, Chin. Phys. B 2015, arXiv preprint arXiv:1505.01640.

[19] M. M. Y. A. Alsaif, K. Latham, M. R. Field, D. D. Yao, N. V. Medehkar, G. A. Beane, R. B. Kaner, S. P. Russo, J. Z. Ou, K. Kalantar-zadeh, Adv. Mater. 2014, 26, 3931.

[20] F. Torrisi, J. N. Coleman, Nat. Nanotechnol. 2014, 9, 738.

[21] F. Torrisi, T. Hasan, W. Wu, Z. Sun, A. Lombardo, T. S. Kulmala, G.-W. Hsieh, S. Jung, F. Bonaccorso, P. J. Paul, D. Chu, A. C. Ferrari, ACS Nano 2012, 6, 2992. 
[22] F. Withers, H. Yang, L. Britnell, A. P. Rooney, E. Lewis, A. Felten, C. R. Woods, V. S. Romaguera, T. Georgiou, A. Eckmann, Y. J. Kim, S. G. Yeates, S. J. Haigh, A. K. Geim, K. S. Novoselov, C. Casiraghi, Nano Lett. 2014, 14, 3987.

[23] J. Z. Ou, J. L. Carnpbell, D. Yao, W. Wlodarski, K. Kalantar-zadeh, J. Phys. Chem. C 2011, 115, 10757.

[24] R. Lampande, G. W. Kim, J. Boizot, Y. J. Kim, R. Pode, J. H. Kwon, J. Mater. Chem. A 2013, 1, 6895 .

[25] S. N. Lou, N. Yap, J. Scott, R. Amal, Y. H. Ng, Sci. Rep. 2014, 4, 7428.

[26] M. E. Spahr, P. Novak, O. Haas, R. Nesper, J. Power Sources 1995, 54, 346.

[27] K. Kalantar-zadeh, J. Tang, M. Wang, K. L. Wang, A. Shailos, K. Galatsis, R. Kojima, V. Strong, A. Lech, W. Wlodarski, R. B. Kaner, Nanoscale 2010, 2, 429.

[28] Y. Wang, J. Z. Ou, A. F. Chrimes, B. J. Carey, T. Daeneke, M. M. Y. A. Alsaif, M. Mortazavi, S. Zhuiykov, N. Medhekar, M. Bhaskaran, J. R. Friend, M. S. Strano, K. KalantarZadeh, Nano Lett. 2015, 15, 883.

[29] M. A. Camacho-Lopez, L. Escobar-Alarcon, M. Picquart, R. Arroyo, G. Cordoba, E. Haro-Poniatowski, Opt. Mater. 2011, 33, 480; G. Mestl, P. Ruiz, B. Delmon, H. Knozinger, J. Phys. Chem. 1994, 98, 11269.

[30] D. M. Koenhen, C. A. Smolders, J. Appl. Polym. Sci. 1975, 19, 1163.

[31] V. Nicolosi, M. Chhowalla, M. G. Kanatzidis, M. S. Strano, J. N. Coleman, Science 2013, 340, 6139.

[32] A. A. Ziabari, S. M. Rozati, Physica B 2012, 407, 4512.

[33] M. T. Greiner, L. Chai, M. G. Helander, W.-M. Tang, Z.-H. Lu, Adv. Funct. Mater. 2012, 22, 4557 .

[34] C. Battaglia, X. Yin, M. Zheng, I. D. Sharp, T. Chen, S. McDonnell, A. Azcatl, C. Carraro, B. Ma, R. Maboudian, R. M. Wallace, A. Javey, Nano Lett. 2014, 14, 967. 
[35] H. Wang, J. Luo, A. Robertson, Y. Ito, W. Yan, V. Lang, M. Zaka, F. Schaffel, M. H. Rummeli, G. A. D. Briggs, J. H. Warner, ACS Nano 2010, 4, 6659.

[36] S. Kim, A. Konar, W.-S. Hwang, J. H. Lee, J. Lee, J. Yang, C. Jung, H. Kim, J.-B. Yoo, J.-Y. Choi, Y. W. Jin, S. Y. Lee, D. Jena, W. Choi, K. Kim, Nat. Commun. 2012, 3 , 1011

[37] O. Katz, A. Horn, G. Bahir, J. Salzman, IEEE Trans. Electron Devices 2003, 50, 2002.

[38] K. Hirakawa, H. Sakaki, Phys. Rev. B 1986, 33, 8291.

[39] W. Zhu, T. Low, Y.-H. Lee, H. Wang, D. B. Farmer, J. Kong, F. Xia, P. Avouris, Nat. Commun. 2014, 5, 3087.

[40] B. Dasgupta, Y. Ren, L. M. Wong, L. Kong, E. S. Tok, W. K. Chim, S. Y. Chiam, J. Phys. Chem. C 2015, 119, 10592. 
a
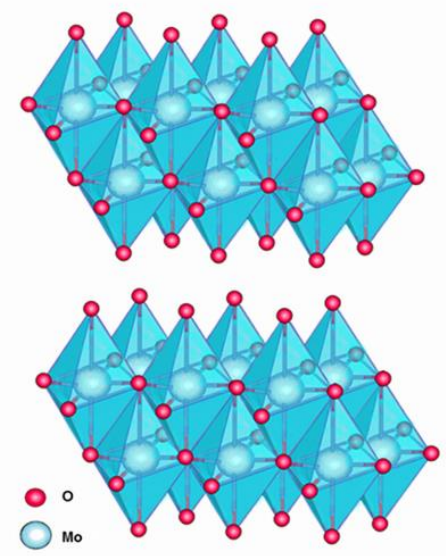

C

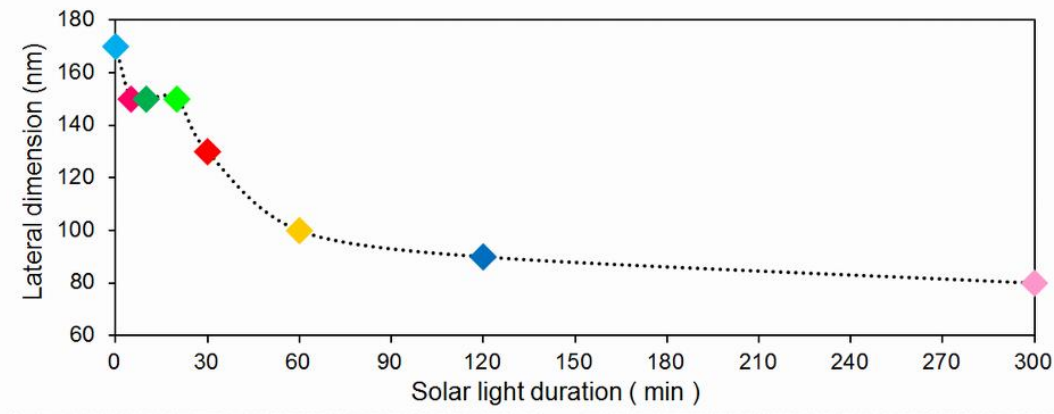

d

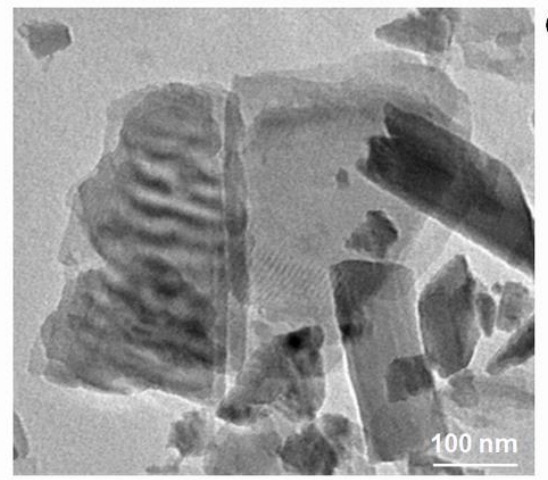

f

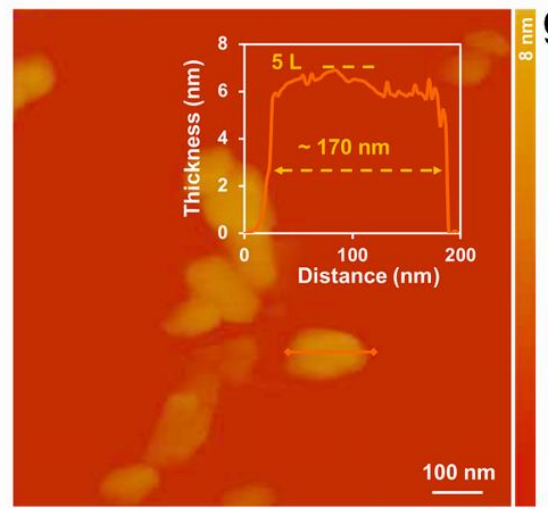

b
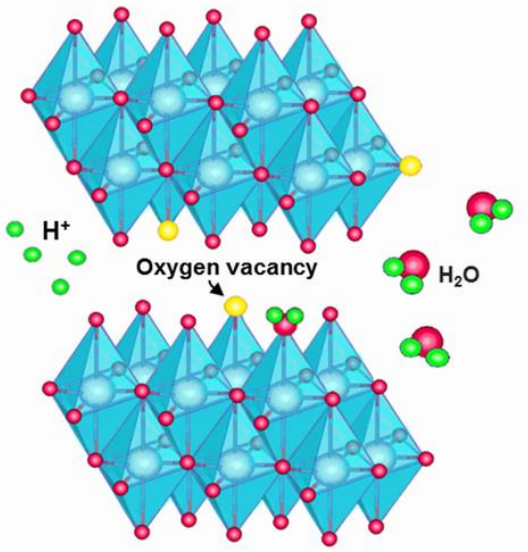
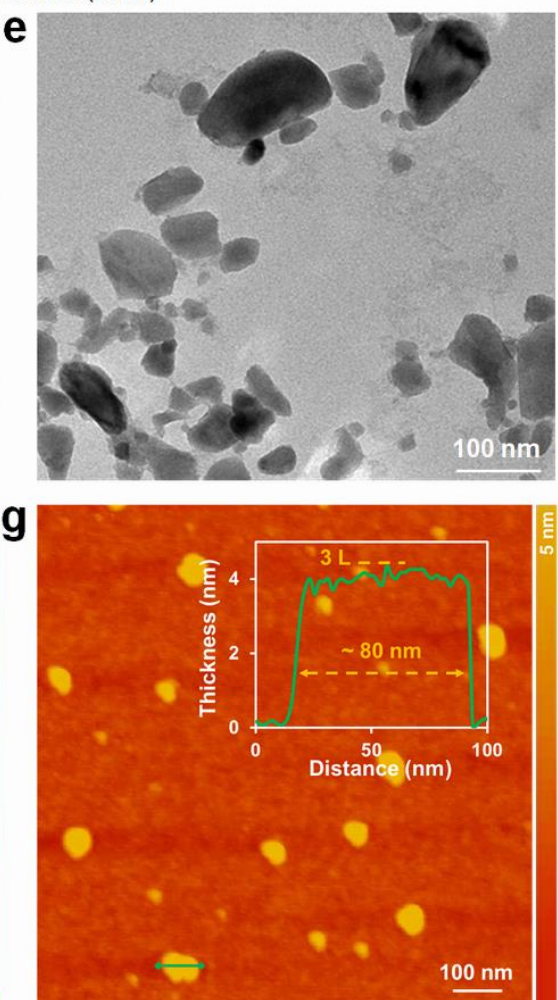

Figure 1. Morphological characterizations of 2D molybdenum oxide flakes. (a) The schematic of $\alpha-\mathrm{MoO}_{3}$. (b) The schematic of hydrogen ions intercalation of $2 \mathrm{D} \alpha-\mathrm{MoO}_{3}$ after solar irradiation. (c) The lateral dimensions of the molybdenum oxide flakes after different durations of simulated solar light irradiation. (d) A TEM image of the initial 2D $\alpha-\mathrm{MoO}_{3}$ nanoflakes. (e) A TEM image of 2D nanoflakes after $5 \mathrm{~h}$ of solar light irradiation. (f) The AFM image of the initial 2D $\mathrm{MoO}_{3}$ nanoflakes with the average thickness of $\sim 5$ layers. $(\mathrm{g})$ The AFM image of 2D nanoflakes after $5 \mathrm{~h}$ of solar light irradiation with the average thickness of $\sim 3$ layers. 


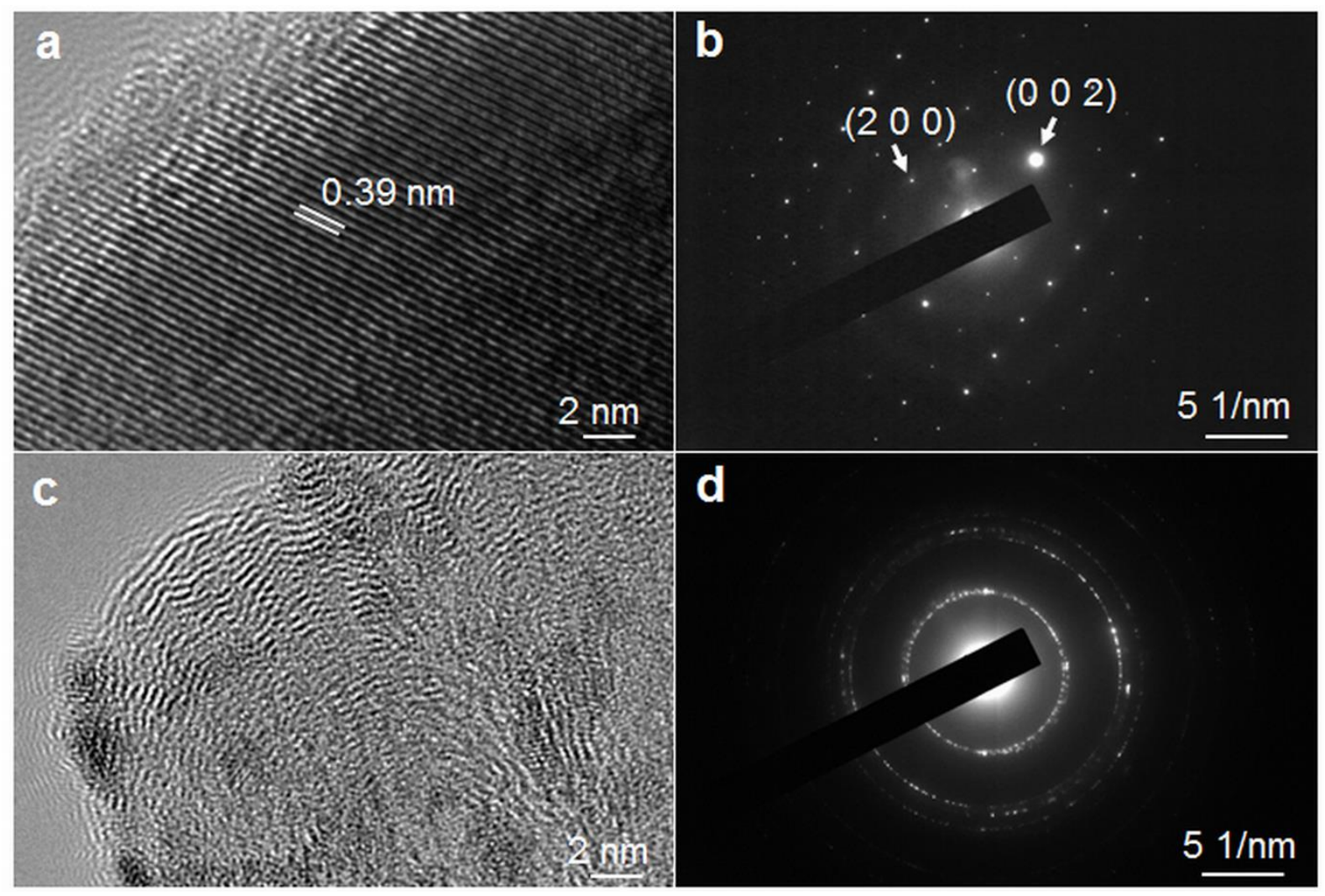

Figure 2. Crystal structures of 2D molybdenum oxide flakes. (a) A HRTEM image of the initial 2D $\alpha-\mathrm{MoO}_{3}$ nanoflake and (b) the corresponding SAED pattern. (c) A HRTEM image of the 2D nanoflake after $5 \mathrm{~h}$ of solar light irradiation and (d) its corresponding SAED pattern. 

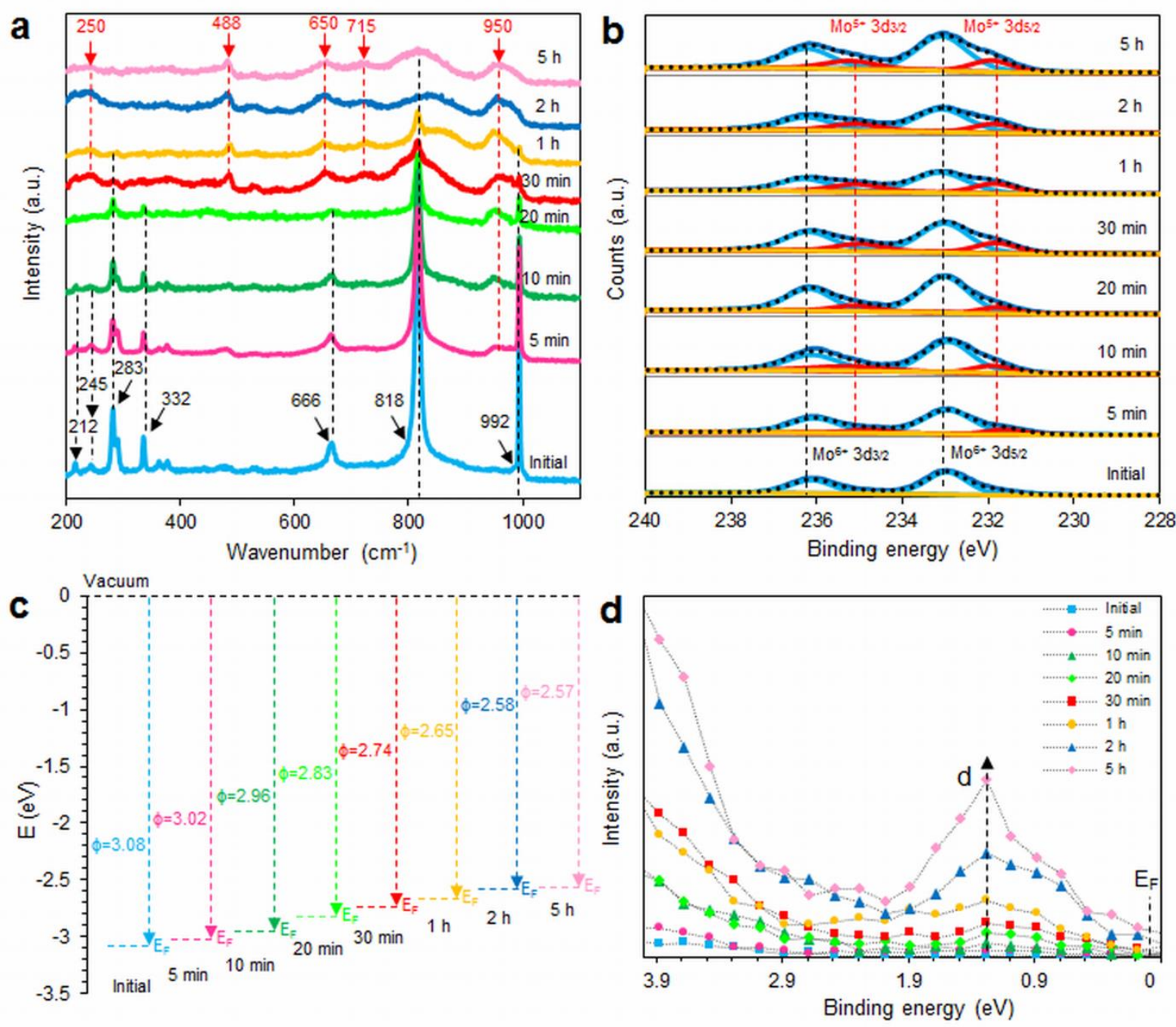

Figure 3. Structural characterizations and electronic band structures of 2D molybdenum oxide flakes obtained at different light exposure durations. (a) The Raman spectra of 2D molybdenum oxide flakes upon different solar light durations. (b) XPS Mo3d spectra of the 2D flakes at different solar light irradiation durations. (c) The energy level diagram with respect to vac showing the $E_{F}$ of the $2 \mathrm{D}$ flakes after different solar irradiation duration. The $E_{F}$ is evaluated from PESA measurements (Figure S7, Supporting Information) and VBM position by photoemission spectroscopy (Figure S8, Supporting Information). (d) The valence photoemission spectra of sub-stoichiometric 2D molybdenum oxides at low binding energy region for different solar irradiation durations. 


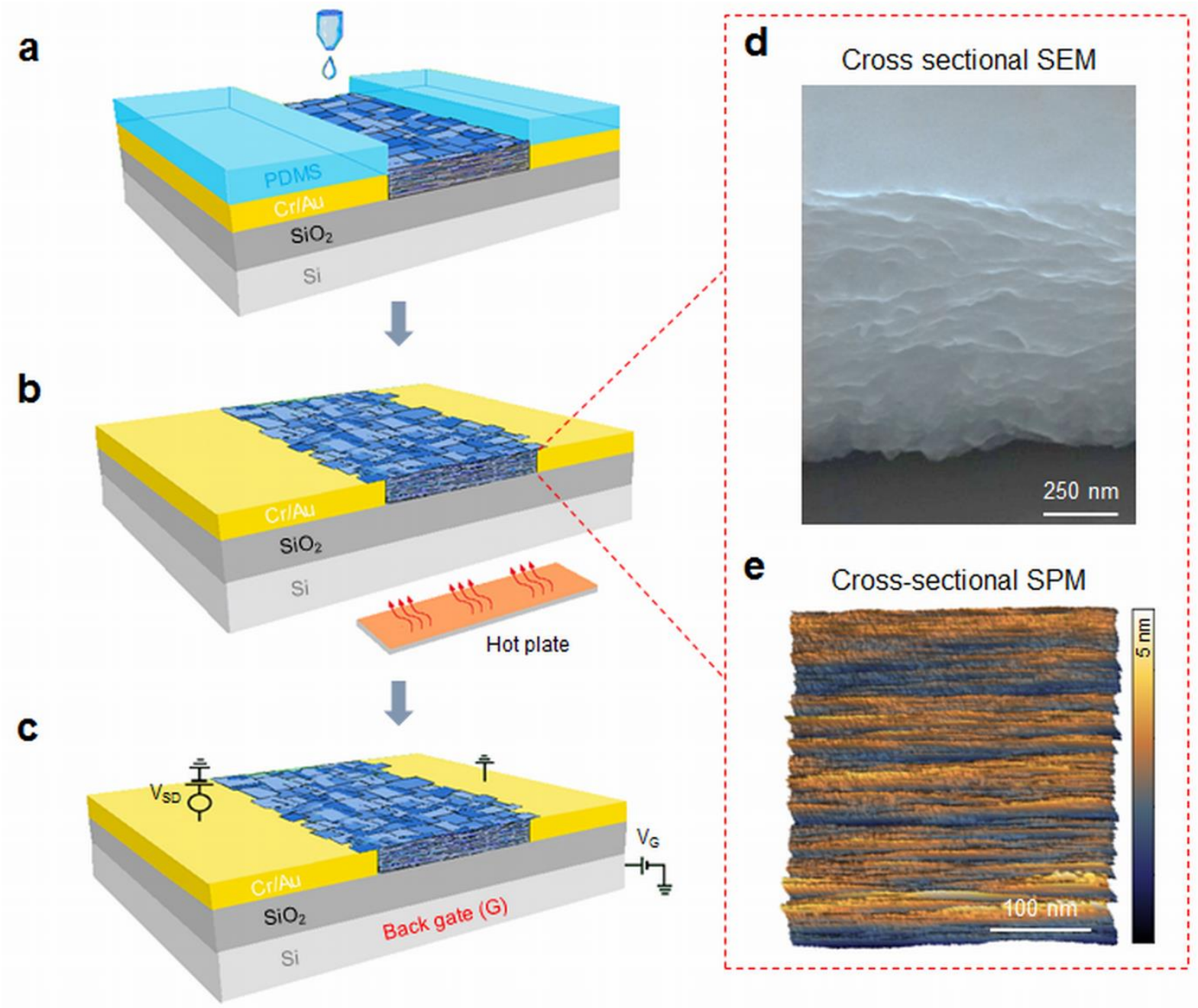

Figure 4. Fabrication of FETs based on 2D molybdenum oxide flakes. (a, b) Illustration of the fabrication steps of a FET based on 2D molybdenum oxide flakes. (c) The configuration diagram of the electrical connections of a FET. (d) Cross-sectional SEM image and (e) crosssectional SPM image revealing that the FET channel is made of orderly re-stacked 2D molybdenum oxide flakes in a planar manner. 

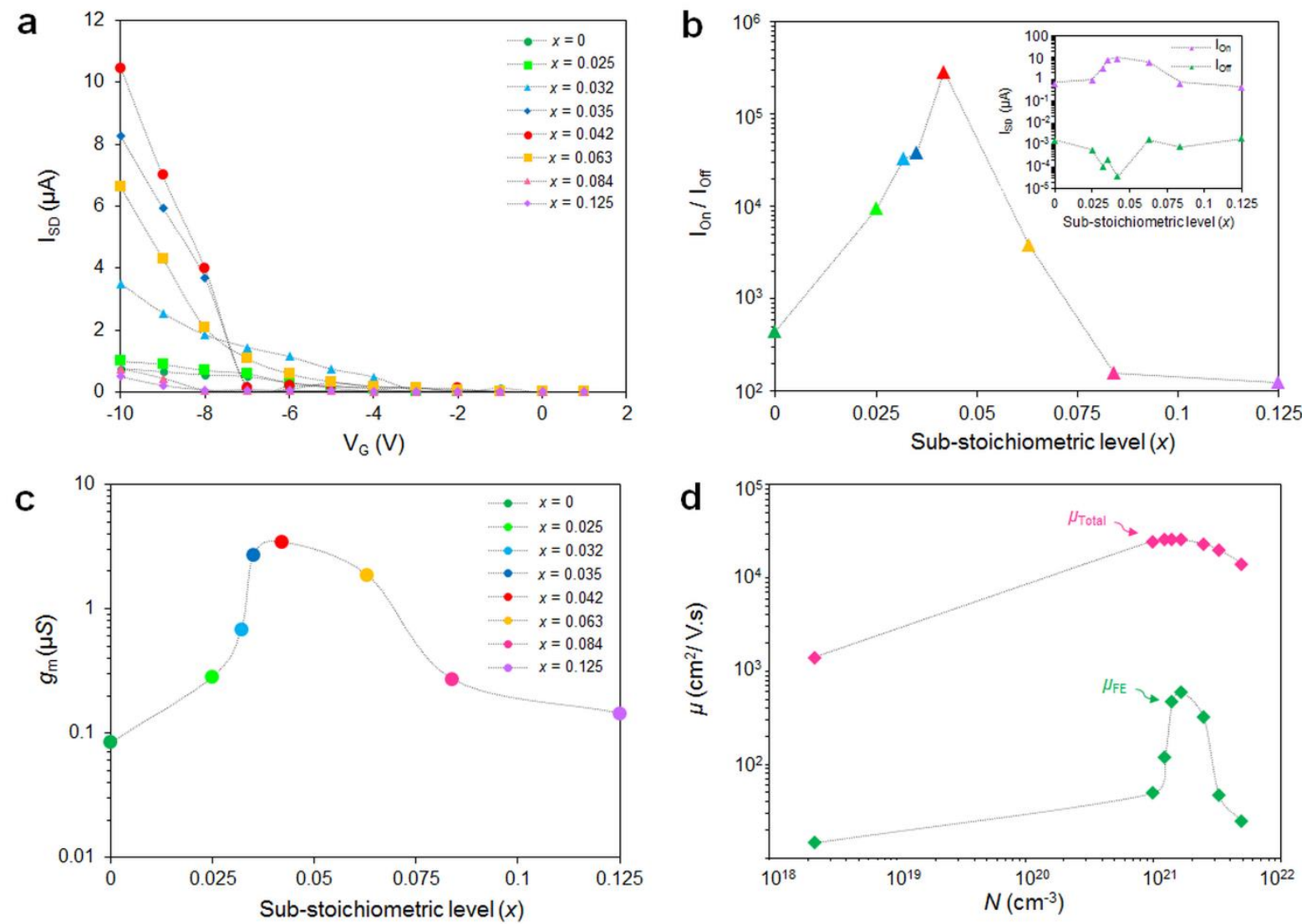

Figure 5. Electrical characteristics of FETs based on films of 2D molybdenum oxide flakes for different sub-stoichiometric levels $(x)$. (a) Current $v s$ applied gate bias for the FETs with different $x$ values and (b) corresponding $\mathrm{I}_{\mathrm{On}} / \mathrm{I}_{\mathrm{Off}}$ ratios for the FETs. The inset is the $\mathrm{I}_{\mathrm{On}}$ and

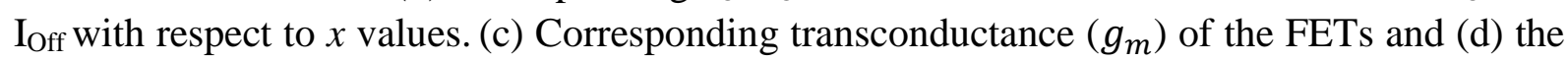
total calculated charge carrier mobility according to Matthiessen's rule and experimental effective mobility as a function of $N$ at room temperature. 
TABLE 1. Summary of materials and corresponding FETs characteristics: (a) estimated free electron concentrations for different solar light durations. (b) Electrical characteristics of FETs based on 2D molybdenum oxides of different sub-stoichiometric levels $(x)$.

(a)

\begin{tabular}{cccc}
\hline Solar light duration & $\mathrm{Mo}^{5+1} \mathrm{Mo}^{6+}$ ratio & $\begin{array}{c}\text { Sub-stoichiometric }(x) \text { of } \\
\mathrm{MoO}_{3-x}\end{array}$ & $\begin{array}{c}\text { Estimated free electron } \\
\text { concentration }\left(\mathrm{cm}^{-3}\right)\end{array}$ \\
\hline Initial $(0 \mathrm{~min})$ & 0 & 0 & $2.24 \times 10^{18[32]}$ \\
$5 \mathrm{~min}$ & 0.050 & 0.025 & $9.85 \times 10^{20}$ \\
$10 \mathrm{~min}$ & 0.063 & 0.032 & $1.23 \times 10^{21}$ \\
$20 \mathrm{~min}$ & 0.071 & 0.036 & $1.41 \times 10^{21}$ \\
$30 \mathrm{~min}$ & 0.083 & 0.042 & $1.64 \times 10^{21}$ \\
$1 \mathrm{~h}$ & 0.125 & 0.063 & $2.46 \times 10^{21}$ \\
$2 \mathrm{~h}$ & 0.167 & 0.084 & $3.28 \times 10^{21}$ \\
$5 \mathrm{~h}$ & 0.250 & 0.125 & $4.92 \times 10^{21}$ \\
\hline
\end{tabular}

(b)

\begin{tabular}{cccc}
\hline Device with $x$ & $\mathrm{I}_{\text {On }} / \mathrm{I}_{\text {Off }}$ ratio & $g_{\mathrm{m}}(\mu \mathrm{S})$ & $\mu_{\mathrm{FE}}\left(\mathrm{cm}^{2} \mathrm{~V}^{-1} \mathrm{~s}^{-1}\right)$ \\
\hline 0 & $4.5 \times 10^{2}$ & \\
\hline .025 & $9.4 \times 10^{3}$ & 0.083 & 14.5 \\
0.032 & $3.2 \times 10^{4}$ & 0.283 & 49.4 \\
0.036 & $3.8 \times 10^{4}$ & 0.683 & 119 \\
0.042 & $3.0 \times 10^{5}$ & 2.70 & 471 \\
0.063 & $3.8 \times 10^{3}$ & 3.45 & 600 \\
0.084 & $1.6 \times 10^{2}$ & 1.85 & 323 \\
0.125 & $1.2 \times 10^{2}$ & 0.268 & 46.8 \\
\hline
\end{tabular}


Electronic inks of 2D $\mathrm{MoO}_{3-x}$ flakes based on a solar light irradiation in liquid-phase exfoliated method are used for developing channels FETs for future high performance printed nanoelectronic devices. We show that the carrier concentrations, energy band, and carrier charge mobilities in $2 \mathrm{D} \mathrm{MoO}_{3-x}$ based FETs can be tuned and the optimal substoichiometric value which the maximum transconductance is obtained.

Keyword: Keywords: two-dimensional, molybdenum oxide, liquid phase exfoliation, field effect transistors, solar light

Manal M. Y. A. Alsaif,* Adam F. Chrimes, Torben Daeneke, Sivacarendran Balendhran, Darin O. Bellisario, Youngwoo Son, Matthew R. Field, Wei Zhang, Hussein Nili, Emily P. Nguyen, Kay Latham, Joel van Embden, Michael S. Strano, Jian Zhen Ou,* and Kourosh Kalantar-zadeh*

Title: High Performance Field Effect Transistors using Electronic Inks of TwoDimensional Molybdenum Oxide Nanoflakes

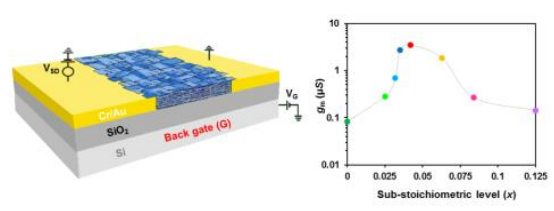

ToC figure 
Copyright WILEY-VCH Verlag GmbH \& Co. KGaA, 69469 Weinheim, Germany, 2013.

\section{Supporting Information}

\section{High Performance Field Effect Transistors using Electronic Inks of Two-Dimensional Molybdenum Oxide Nanoflakes}

Manal M. Y. A. Alsaif, * Adam F. Chrimes, Torben Daeneke, Sivacarendran Balendhran, Darin O. Bellisario, Youngwoo Son, Matthew R. Field, Wei Zhang ${ }^{1}$, Hussein Nili, Emily P. Nguyen, Kay Latham, Joel van Embden, Michael S. Strano, Jian Zhen Ou, * and Kourosh Kalantar-zadeh*

Miss. M. M. Y. A. Alsaif, Dr. T. Daeneke A. F. Chrimes, Dr. T. Daeneke, Mr. W. Zhang, Miss. Emily P. Nguyen, Dr. J. Z. Ou, Prof. K. Kalantar-zadeh

School of Electrical and Computer Engineering, RMIT University, Melbourne, Victoria 3001, Australia

E-mail: s3372431@student.rmit.edu.au

E-mail: jianzhen.ou@rmit.edu.au

E-mail: kourosh.kalantar@rmit.edu.au

Dr. S. Balendhran, Mr. H. Nili

Functional Materials and Microsystems Research Group, RMIT University, Melbourne, Victoria 3001, Australia

Mr. D. O. Bellisario, Mr.Y. Son, Prof. M. S. Strano

Department of Chemical Engineering, Massachusetts Institute of Technology, Cambridge, Massachusetts 02139 United States

Dr. M. R. Field

RMIT Microscopy and Microanalysis Facility, RMIT University, Melbourne, Australia

Prof. K. Latham

School of Applied Sciences, RMIT University, Melbourne VIC 3001, Australia

J. V. Embden

CSIRO Manufacturing Flagship, Bayview Avenue, Clayton, Victoria 3168, Australia 


\section{Supporting Information Note 1: Energy band diagram of 2D $\alpha-\mathrm{MoO}_{3}$ :}

Upon photo-excitation of the exfoliated sample of $\alpha-\mathrm{MoO}_{3}$ by simulated solar light, electronhole pairs are formed (Figure S1, Supporting Information). ${ }^{[1]}$ The photogenerated holes oxidize water molecules to establish oxygen and proton entities. ${ }^{[1,2]}$

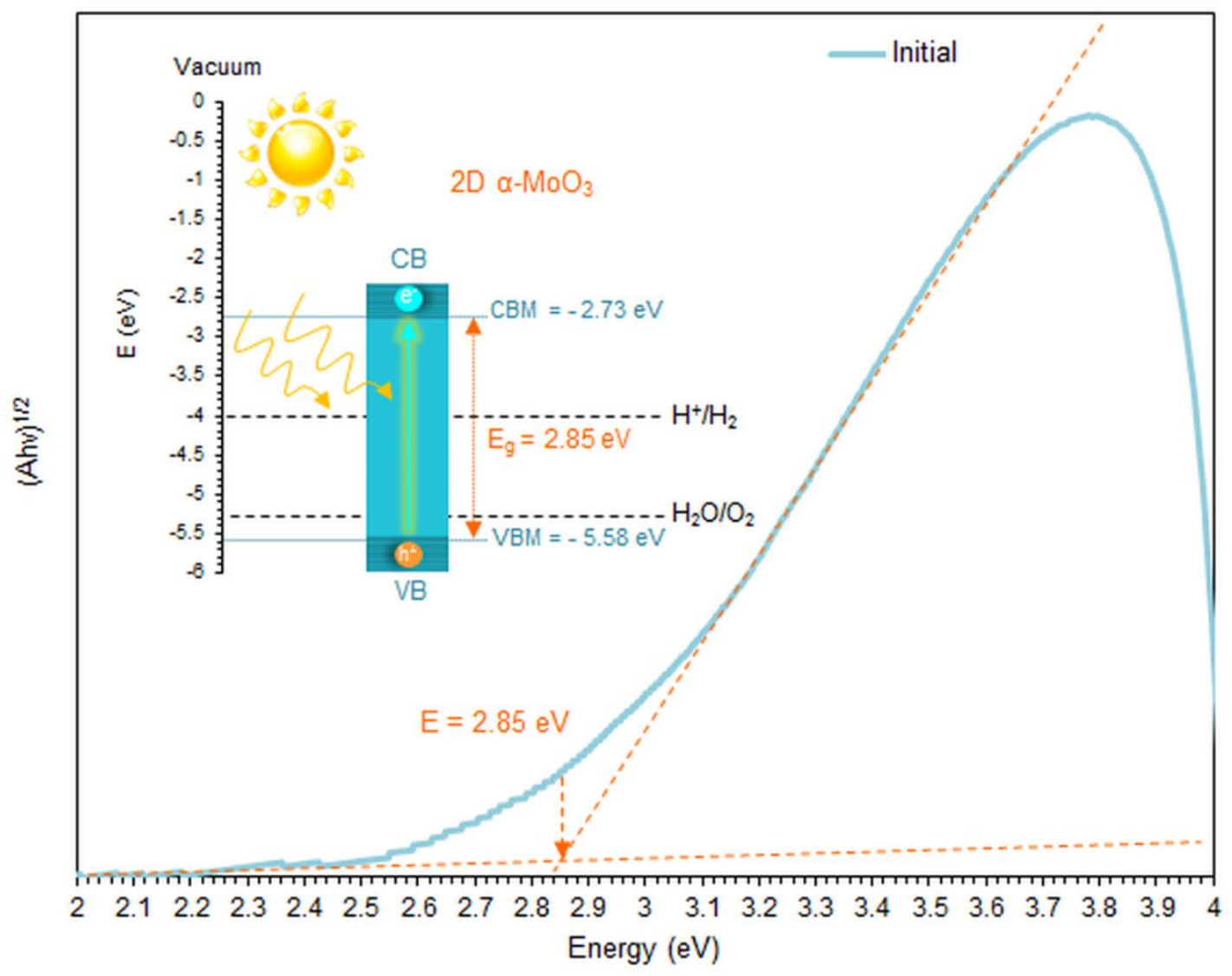

Figure S1. Tauc plot of the form $(\mathrm{Ahv})^{1 / 2}$ used to determine the indirect $E_{g}$ of 2D $\alpha$ $\mathrm{MoO}_{3} \cdot{ }^{[3]}$ ENREF 1 An indirect $E_{g}$ of approximately $2.85 \mathrm{eV}$ was extrapolated. The inset is the extrapolated energy band diagram of $2 \mathrm{D} \alpha-\mathrm{MoO}_{3}$ with respect to vac measured using Tauc analysis. The $I E$ of the initial sample is determined by assistance of PESA (Figure S7a, Supporting Information). The vac level is taken as zero reference. The dotted lines indicate the water reduction $\left(\mathrm{H}^{+} / \mathrm{H}_{2} \sim-4 \mathrm{eV}\right.$ respect to vac $)$ and oxidation $\left(\mathrm{H}_{2} \mathrm{O} / \mathrm{O}_{2} \sim-5.3 \mathrm{eV}\right.$ respect to $v a c$ ) potentials at our reaction conditions $(\mathrm{pH}=6-7)$. 


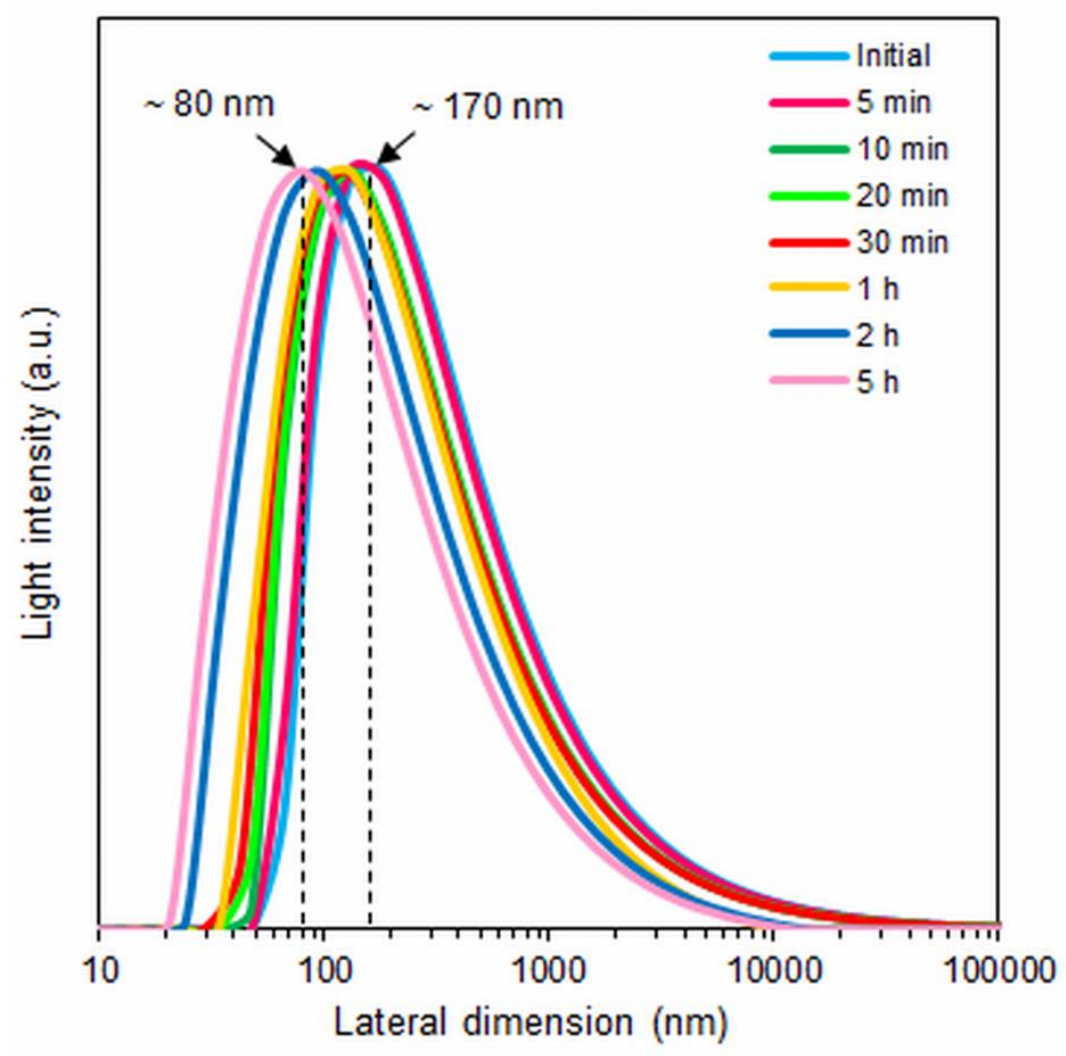

Figure S2. The DLS diagram of 2D molybdenum oxides flakes for different durations of the solar light irradiation. 

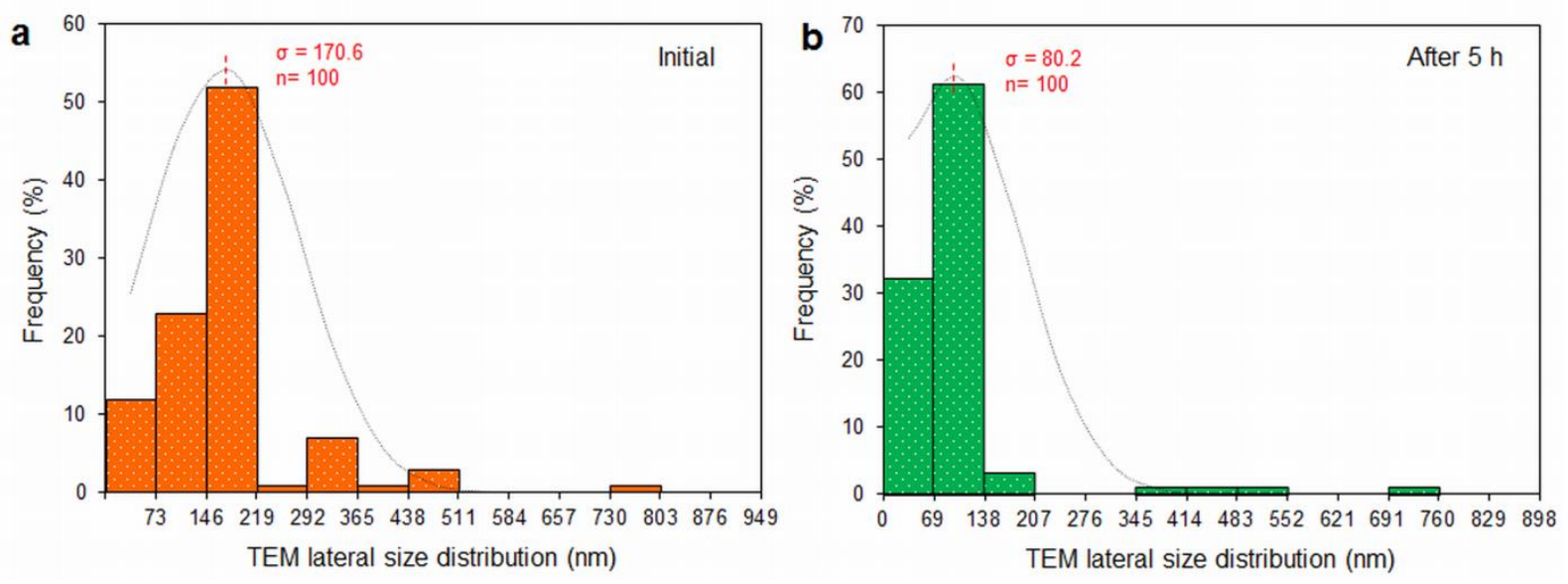

Figure S3. Histograms showing the distribution of 2D molybdenum oxide nanoflakes lateral dimensions before and after $5 \mathrm{~h}$ of solar light irradiation. The histograms are sampled using 100 flakes each. 

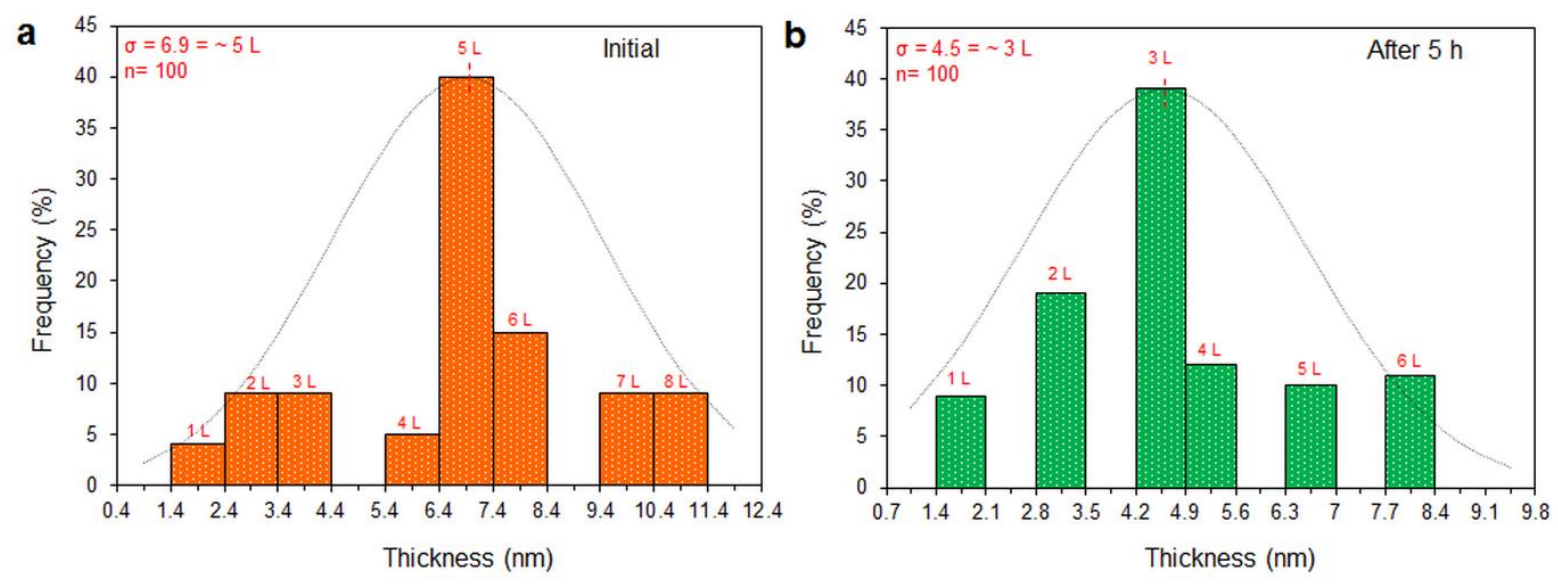

Figure S4. Histograms showing the distribution of 2D molybdenum oxide nanoflakes thickness before and after $5 \mathrm{~h}$ of solar light irradiation. The histograms were sampled using 100 flakes each. 


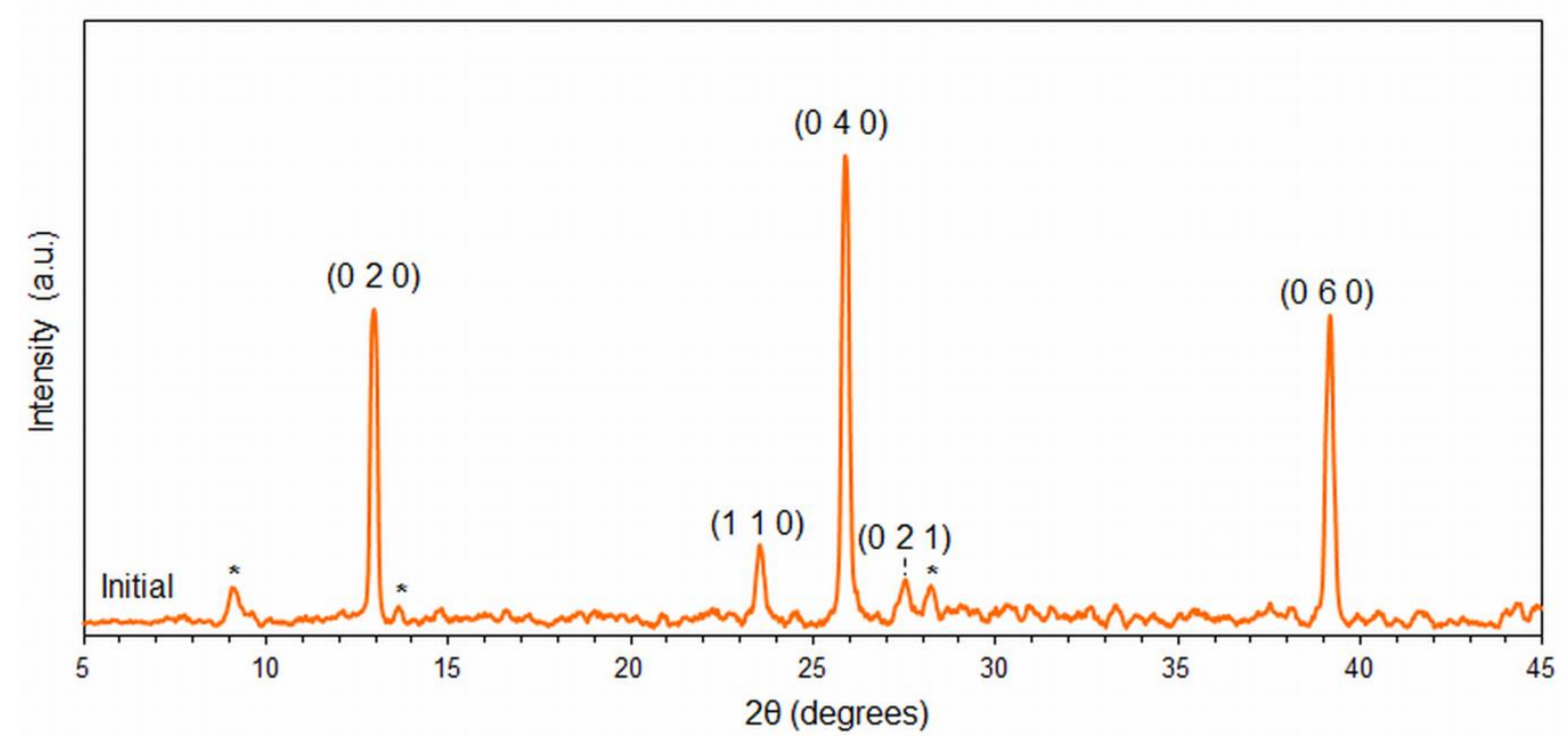

Figure S5. The XRD pattern of the initial film made of 2D molybdenum oxide flakes. The XRD pattern shows that the flakes are made of crystalline orthorhombic $\alpha-\mathrm{MoO}_{3}$ with lattice parameters of $a=3.697 \AA, b=13.858 \AA, c=3.962 \AA$ (ICDD no: 35-0609) and minor contribution of slightly hydrated $\mathrm{MoO}_{3}$ ENREF_26. The dominant peaks observed at 12.8,

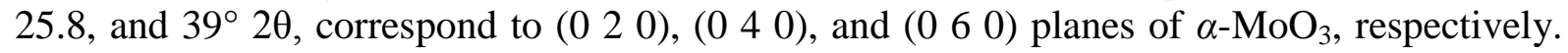
Peaks corresponding to hydrated $\mathrm{MoO}_{3}$ are denoted by [*]. 


\section{Supporting Information Note 2: Discussion on Raman spectra:}

The $283 \mathrm{~cm}^{-1}$ peak represents the bending mode for the double bond $(\mathrm{Mo}=\mathrm{O})$ vibration. ${ }^{[2,4]}$ The $666 \mathrm{~cm}^{-1}$ peak is assigned to the tri-coordinated oxygen $\left(\mathrm{Mo}_{3}-\mathrm{O}\right)$ stretching mode, which results from edge-shared oxygen atoms in common to three adjacent octahedra. ${ }^{[2,}$ ${ }^{4]}$ ENREF 4 The $818 \mathrm{~cm}^{-1}$ peak is related to the bi-coordinated oxygen $\left(\mathrm{Mo}_{2}-\mathrm{O}\right)$ stretching mode, which results from corner-sharing oxygen atoms common to two octahedra. ${ }^{[2,4]}$ The $992 \mathrm{~cm}^{-1}$ peak is assigned to the terminal oxygen $(\mathrm{Mo}=\mathrm{O})$ stretching mode, which results from an unshared oxygen. ${ }^{[2]}$ In addition, the peak at $332 \mathrm{~cm}^{-1}$ can be assigned to $\mathrm{Mo}_{3}-\mathrm{O}$ and the two weak peaks at 212 and $245 \mathrm{~cm}^{-1}$ both represent the bending modes of $\mathrm{Mo}_{2}-\mathrm{O}^{[2]}$ 


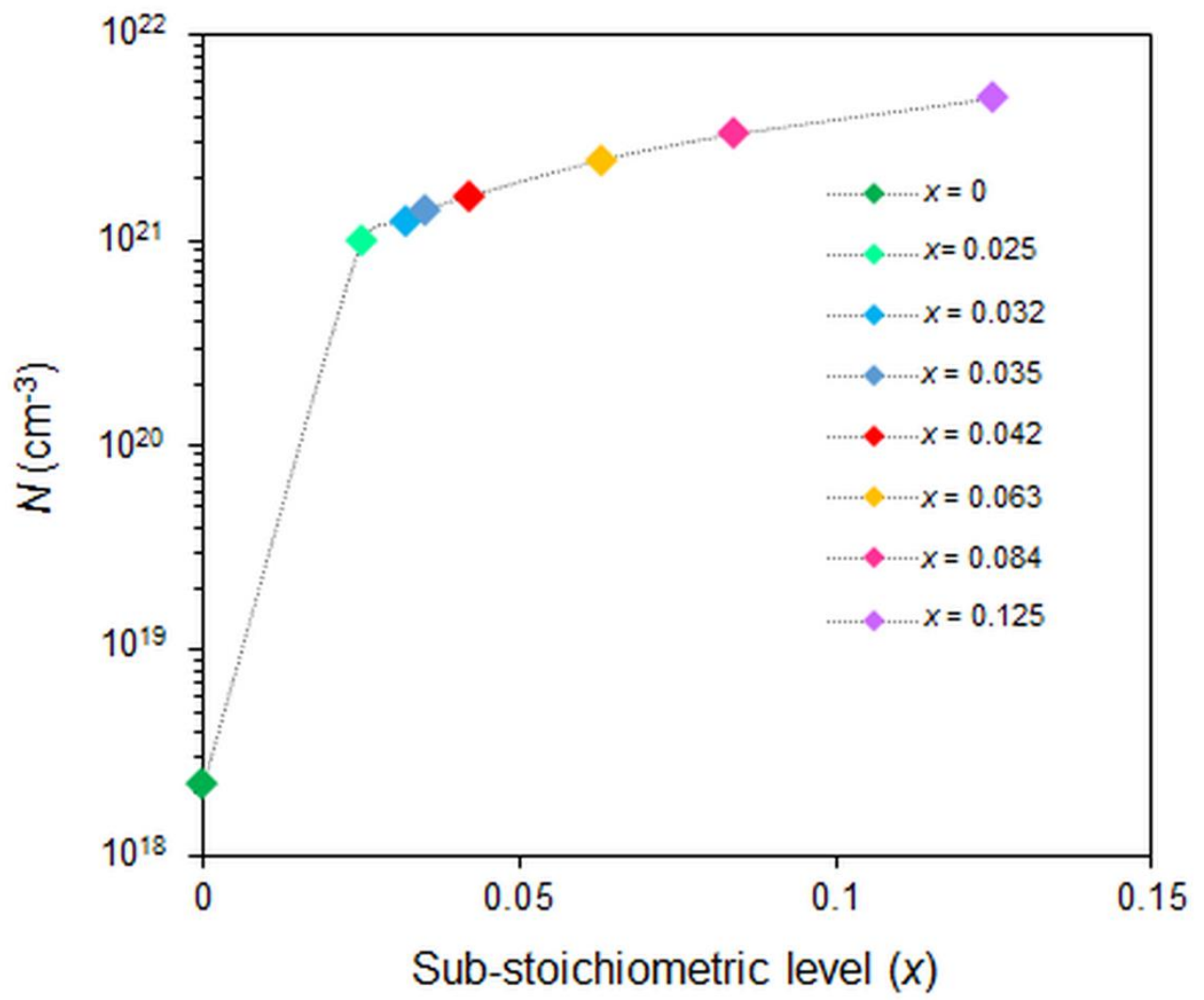

Figure S6. The estimated free electron concentration of $\mathrm{MoO}_{3-x}$ as a function of substoichiometric levels $(x)$ by assuming one oxygen vacancy generates two free electrons. 

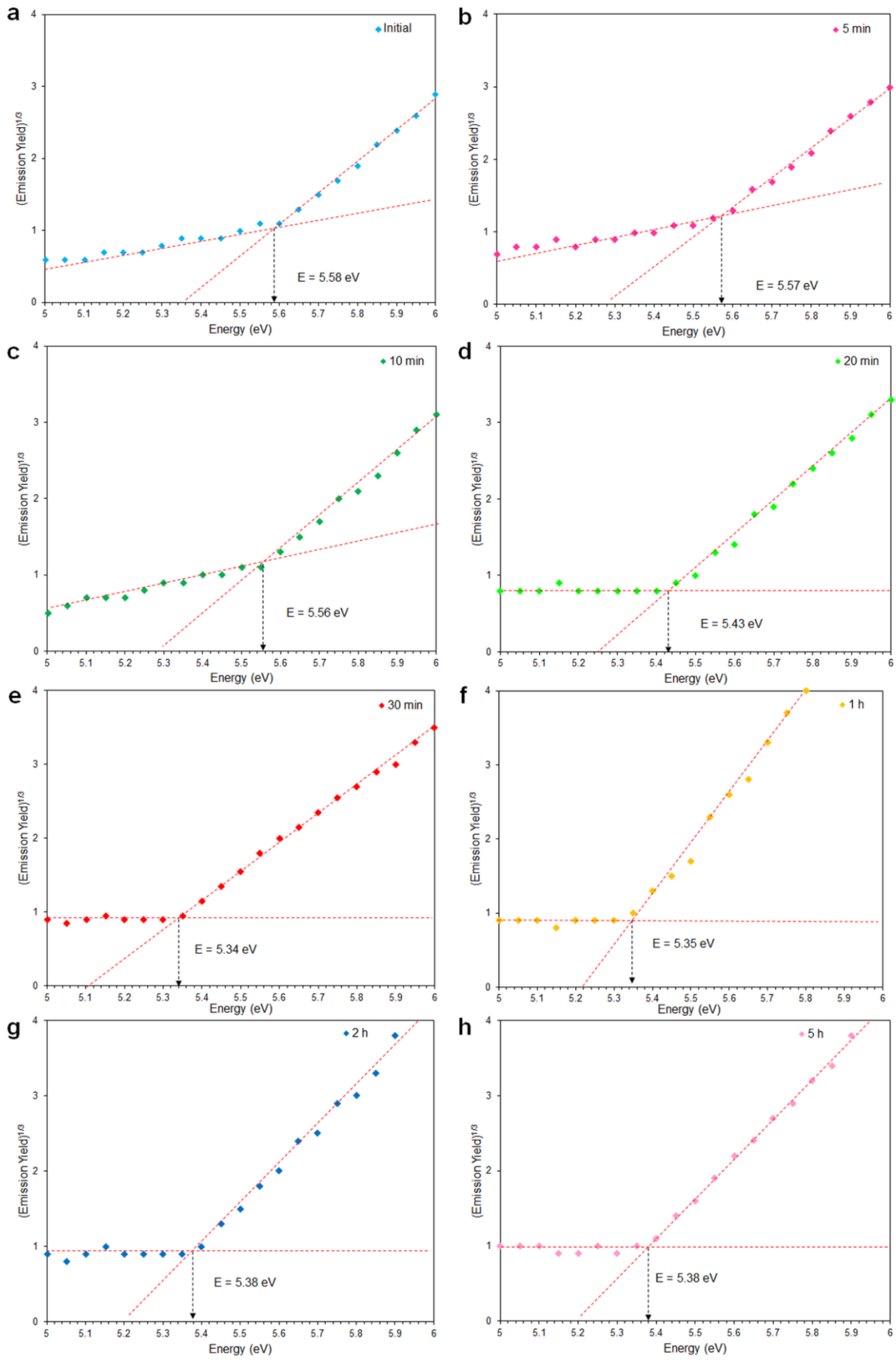

Figure S7. PESA measurements on a thin-film made of sub-stoichiometric molybdenum oxide flakes, and the determination of VBM from PESA measurements._ENREF_1 ${ }^{[3]}$ 

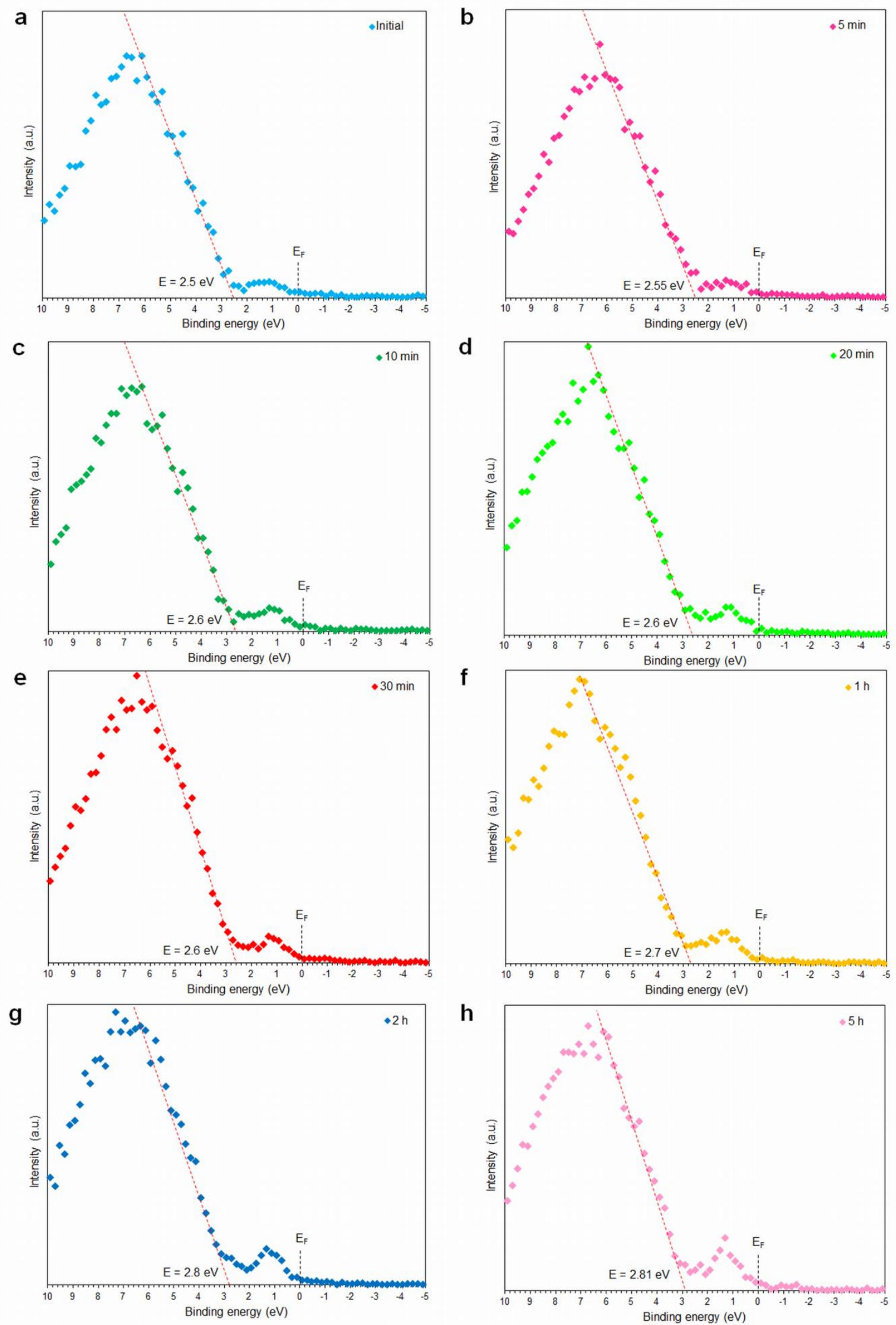

Figure S8. The valence photoemission spectra of sub-stoichiometric molybdenum oxide at low binding energy region near $E_{F}$ under different solar time irradiation. ${ }^{[5]}$ ENREF_2 
Table S1. The summary values used in the energy level diagram of the $2 \mathrm{D}$ molybdenum oxide flakes at different solar irradiation durations

\begin{tabular}{|c|c|c|c|c|c|c|c|c|}
\hline Solar light duration & Initial & $5 \min$ & $10 \min$ & $20 \min$ & $30 \mathrm{~min}$ & $1 \mathrm{~h}$ & $2 \mathrm{~h}$ & $5 \mathrm{~h}$ \\
\hline$I E(\mathrm{eV})$ & 5.58 & 5.57 & 5.56 & 5.43 & 5.34 & 5.35 & 5.38 & 5.38 \\
\hline $\begin{aligned} E= & \text { relative position of } E_{F} \text { with } \\
& \text { respect to } E_{V B} \text { edge }(\mathrm{eV})\end{aligned}$ & 2.50 & 2.55 & 2.60 & 2.60 & 2.60 & 2.70 & 2.80 & 2.81 \\
\hline$\phi(\mathrm{eV})=I E-E$ & 3.08 & 3.02 & 2.96 & 2.83 & 2.74 & 2.65 & 2.58 & 2.57 \\
\hline
\end{tabular}



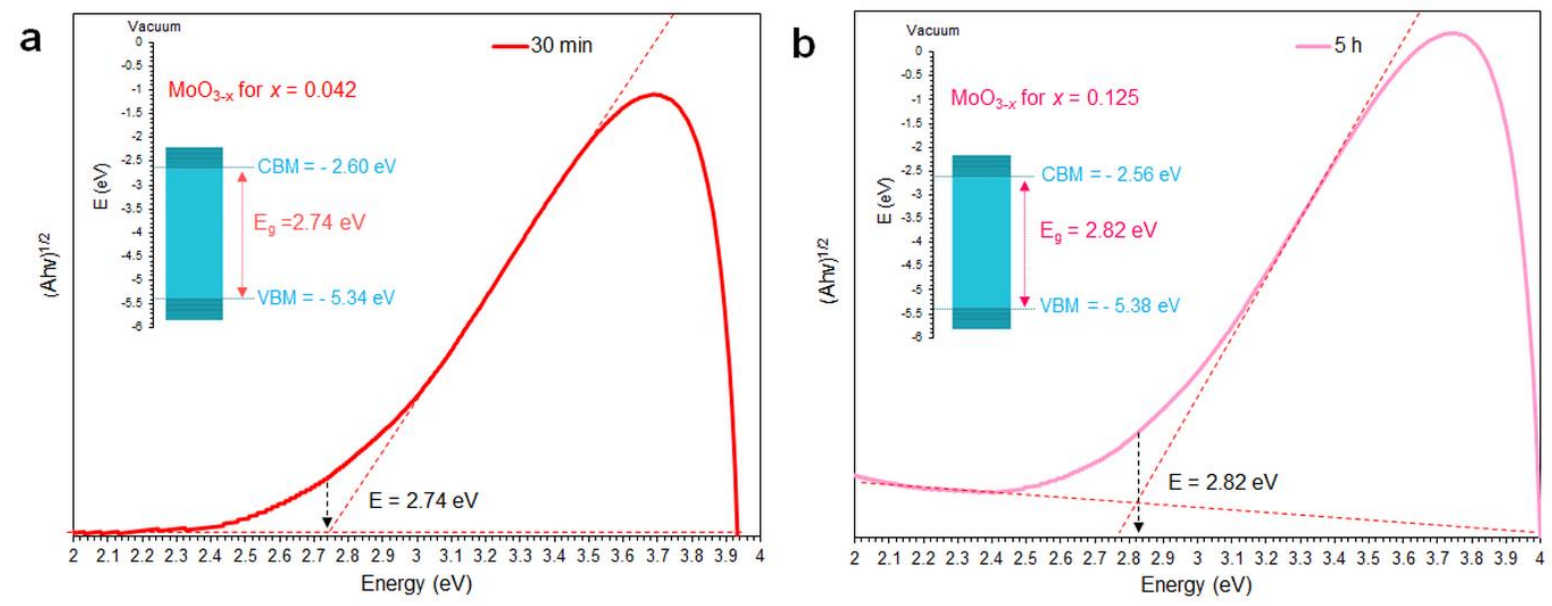

Figure S9. Electronic band structure estimation of sub-stoichiometric molybdneum oxide flakes. (a)Tauc plot the form (Ahv) ${ }^{1 / 2}$ used to determine the $E_{g}$ of $2 \mathrm{D} \mathrm{MoO}_{3-x}$ at $30 \mathrm{~min}$ of solar light irradiation. The inset is the extrapolated $E_{g}$ of $2 \mathrm{D} \alpha-\mathrm{MoO}_{3-x}$ with respect to vac measured using Tauc analysis and PESA (Figure S7e, Supporting Information). (b) Tauc plot of $2 \mathrm{D} \mathrm{MoO}_{3-x}$ at $5 \mathrm{~h}$ of solar light irradiation. The inset is the extrapolated energy band diagram of $2 \mathrm{D} \mathrm{MoO}_{3-x}$ with respect to vac measured using Tauc analysis and PESA (Figure $\mathrm{S} 7 \mathrm{~h}$, Supporting Information). 

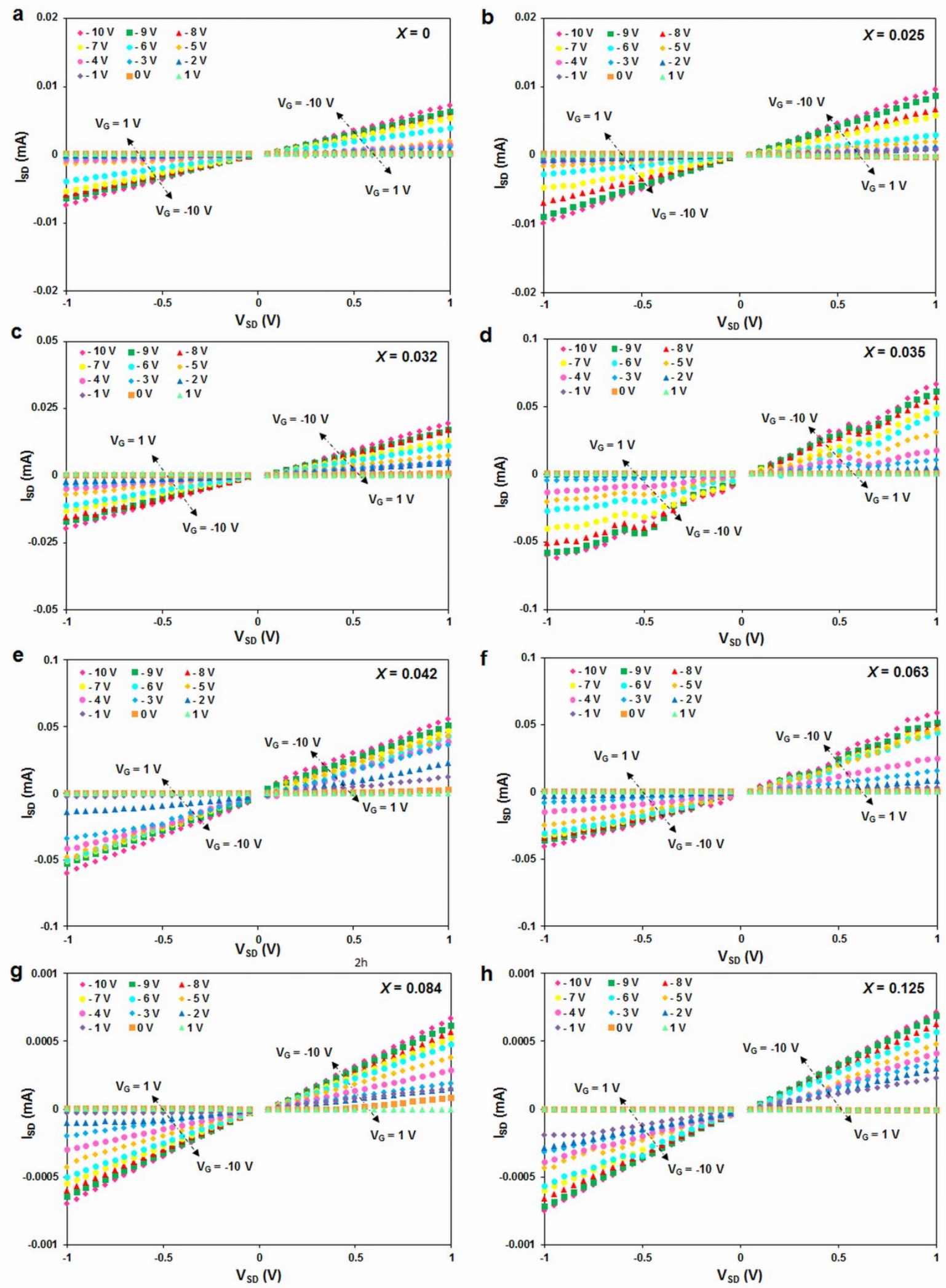

Figure S10. The I-V curves for FETs made from different sub-stoichiometric levels $(x)$ of $\mathrm{MoO}_{3-x}$ for applied gate bias voltages ranged from -10 to $1 \mathrm{~V}$. 


\section{Supporting Information Note 3: 2D electron mobility charge transport calculation of} sub-stoichiometric molybdenum oxide

1. The electron mobility is limited by the ionized charge scattering due to doped electron charges (remote donors) in the depletion layer and is given by: ${ }^{[6]}$ ENREF 4

$$
\mu_{\mathrm{I}}=\frac{64 \pi \hbar^{3} \varepsilon_{s}{ }^{2} \mathrm{~S}_{\mathrm{o}}{ }^{2}\left(2 \pi n_{2 D}\right)^{3 / 2}}{e^{3} \mathrm{~m}^{* 2} N}\left[\frac{1}{\left(\mathrm{Z}_{\mathrm{o}}\right)^{2}}-\frac{1}{\left(\mathrm{~d}+\mathrm{Z}_{\mathrm{o}}\right)^{2}}\right]^{-1}
$$

where $\varepsilon_{S}$ is the relative static dielectric constants of the semiconductor $\left(\varepsilon_{s}=35 \varepsilon_{o} \mathrm{~F} \mathrm{~m}^{-}\right.$ $\left.{ }^{1}\right),{ }^{[7]}$ ENREF 5 ENREF 5 is the reduced Planck constant, $e$ is the electron charge, $\mathrm{m}^{*}$ is the electron effective mass $\left(\mathrm{m}^{*}=0.2 \times \mathrm{m}_{0}=1.82 \times 10^{-31} \mathrm{~kg}\right),{ }^{[2]}$ ENREF $55 n_{2 D}$ is the 2D sheet carrier density $\left(n_{2 D}=N \times \mathrm{d}\right)$ and $N$ is the free electron concentration, $\mathrm{Z}_{\mathrm{o}}$ is the width of the quantum well $\left(\mathrm{Z}_{\mathrm{o}}=1.23 \times 10^{-10} \mathrm{~m}\right),{ }^{[8]}$ ENREF 6 and $\mathrm{d}$ is the width of doped depletion layer $(\mathrm{d}$ $\left.=15 \times 10^{-9} \mathrm{~m}\right)$. ENREF $7^{[9]}$ The screening constant $\mathrm{S}_{\mathrm{o}}$ is given by:

$$
\mathrm{S}_{\mathrm{o}}=\frac{e^{2} \mathrm{~m}^{*}}{2 \pi \varepsilon_{S} \hbar^{2}}
$$

2. The lattice vibration scattering mobility in terms of acoustic deformation potential scattering is given by: ${ }^{[10]}$ ENREF 8

$$
\mu_{\mathrm{AD}}=\left(\left(\frac{\pi}{3}\right)^{\frac{1}{3}}\right) \frac{e \hbar^{3} C_{1}}{\left(\mathrm{~m}^{*}\right)^{2}\left(\mathrm{E}_{\mathrm{d}}\right)^{2} \mathrm{~K}_{\mathrm{B}} \mathrm{T} N^{\frac{1}{3}}},
$$

where $C_{l}$ is the elasticity modulus $\left(C_{l}=3.1 \times 10^{10} \mathrm{~N} / \mathrm{m}^{2}\right) .{ }^{[11]}$ ENREF 9

3. The electron mobility related optical phonon scattering is given by: ${ }^{[12]}$ ENREF 10

$$
\begin{gathered}
\mu_{\mathrm{OP}}=\frac{\varepsilon_{o p} k_{o} \hbar^{2}}{2 \pi e \omega_{o p} \mathrm{~m}^{* 2} N_{f} \mathrm{G}\left(k_{o}\right)}\left(1+\frac{1-\exp (-y)}{y}\right), \\
y=\frac{\pi \hbar^{2} n_{2 D}}{\mathrm{~m}^{*} \mathrm{~K}_{\mathrm{B}} \mathrm{T}}, \quad \text { (S5) } \\
k_{o}=\sqrt{\frac{2 \mathrm{~m}^{*} \omega_{o p}}{\hbar}}, \quad \text { (S6) }
\end{gathered}
$$




$$
\varepsilon_{o p}=\left[1 / \varepsilon_{\infty}-1 / \varepsilon_{\mathrm{s}}\right]^{-1}
$$

where $\omega_{o p}$ is longitudinal optical phonon angular frequency $\left(\omega_{o p}=3.43 \times 10^{15} \mathrm{rad} . \mathrm{s}^{-1}\right),{ }^{[13]}$ and ENREF $11 \varepsilon_{\infty}$ is the dielectric constant at high frequencies $\left(\varepsilon_{\infty}=20 \varepsilon_{o} \mathrm{~F} \mathrm{~m}^{-1}\right) .^{[2]}$ ENREF 6

\section{ENREF_12}

In equation ( $\mathrm{S} 4), \mathrm{G}\left(k_{o}\right)$ is calculated using the variation electron wave function and it is given by:

$$
\mathrm{G}\left(k_{o}\right)=\frac{b\left(8 b^{2}+9 k_{o} b+3 k_{o}^{2}\right)}{8\left(k_{o}+b\right)^{3}}
$$

in which $N_{f}$ is the phonon Planck distribution function (Bose-Einstein function) and it is given by:

$$
N_{f}=\frac{1}{\left[\exp \left(\frac{\hbar \omega_{o p}}{\mathrm{~K}_{\mathrm{B}} \mathrm{T}}\right)\right]^{-1}}
$$

where the variation parameter $b$ is given by:

$$
b=\left(\frac{33 \pi \mathrm{m}^{*} e^{2} n_{2 D}}{2 k_{o} \hbar^{2}}\right)^{1 / 3}
$$




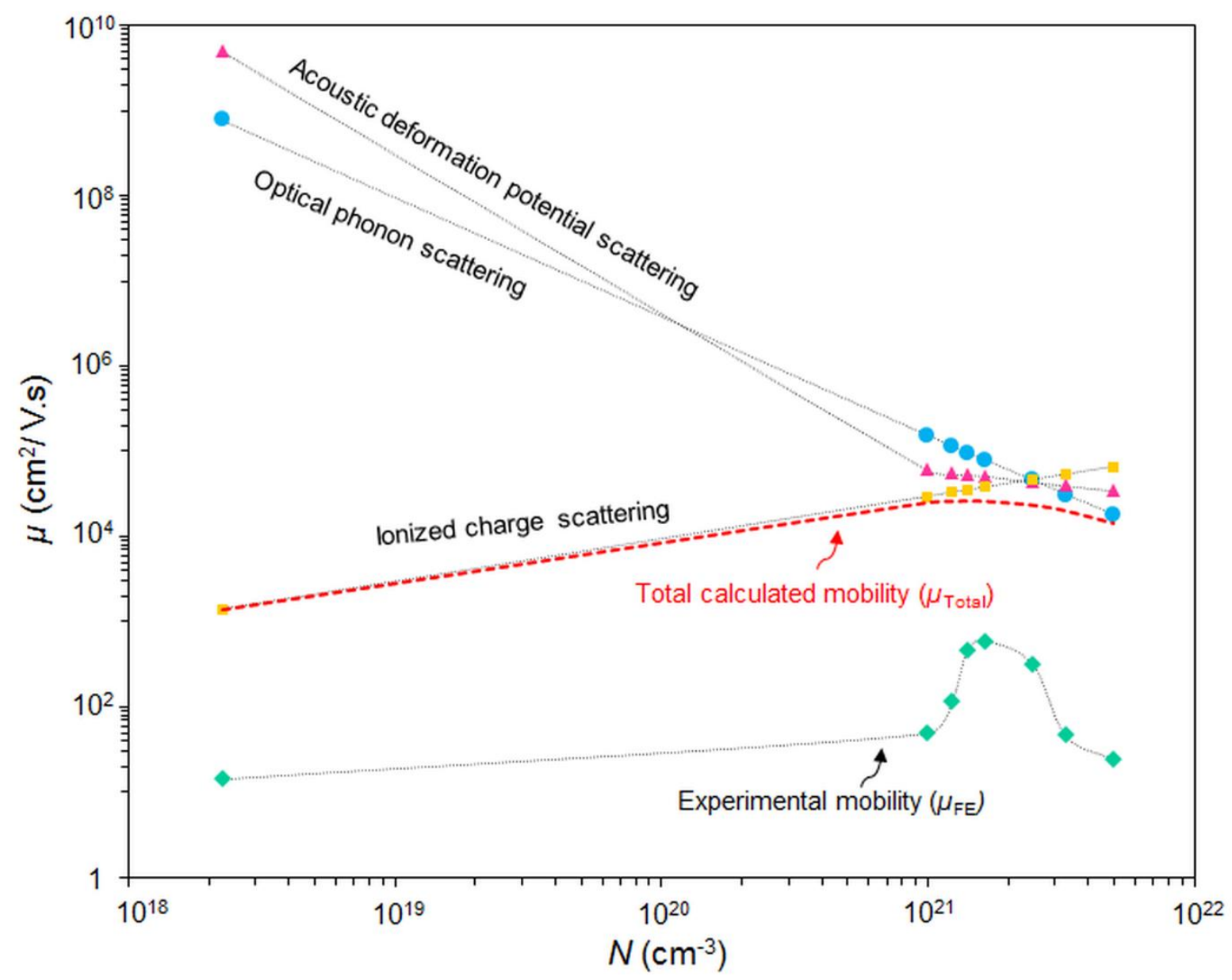

Figure S11. The total calculated mobility of 2D molybdenum oxide as a function of $N$ at 300 $\mathrm{K}$ for acoustic deformation potential scattering, optical phonon scattering and ionized charge scattering as well as the experimental mobility. The total calculated mobility is the inverse mobility for all scattering according to Matthiessen's rule as: $\mu_{\mathrm{Total}}{ }^{-1}=\mu_{\mathrm{I}}^{-1}+\mu_{\mathrm{AD}}{ }^{-1}+\mu_{\mathrm{OP}}{ }^{-1}$ (red dash line). 


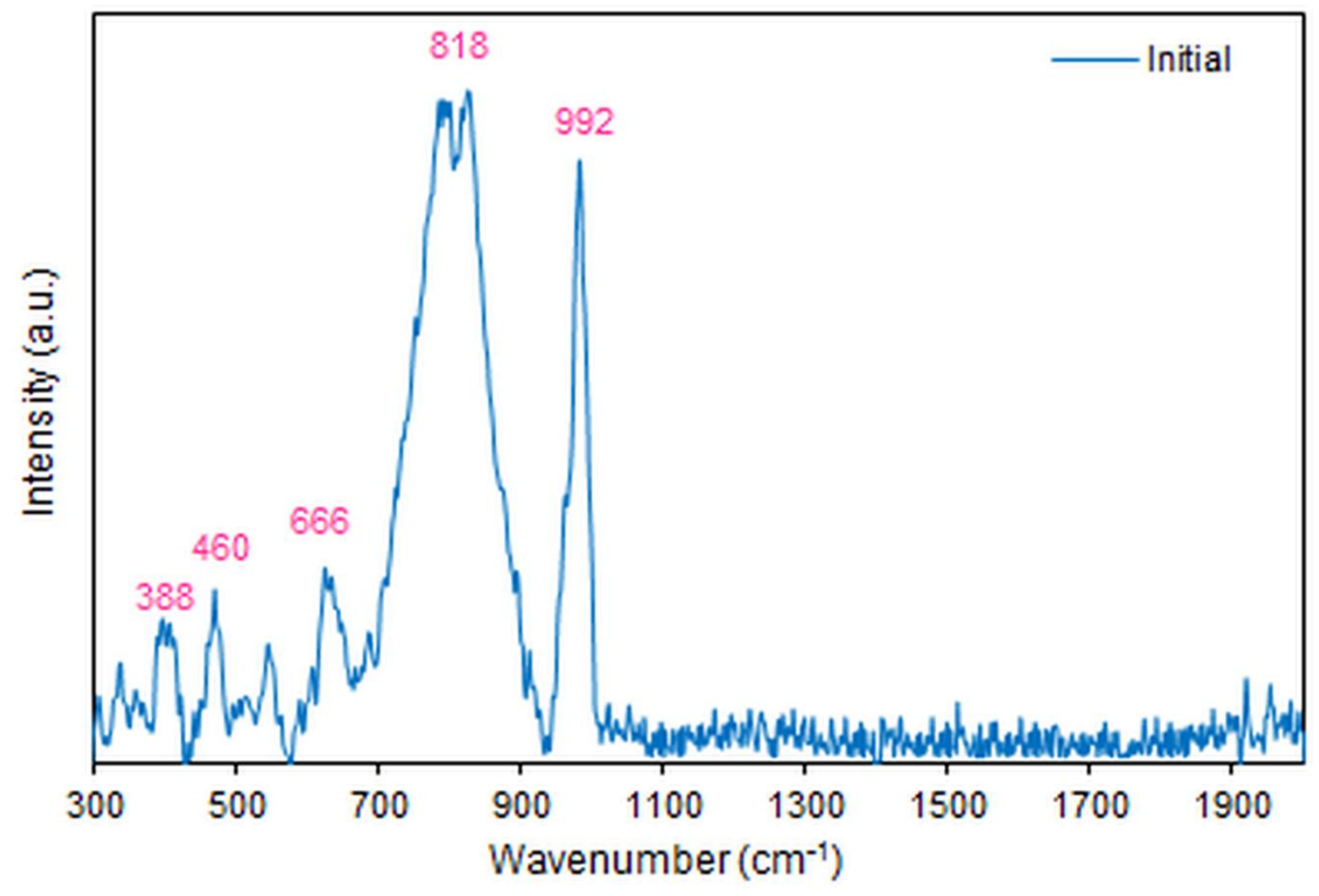

Figure S12. The extended Raman spectrum of the drop-casted film made of $2 \mathrm{D} \alpha-\mathrm{MoO}_{3}$ nanoflakes that was annealed at $75{ }^{\circ} \mathrm{C} .{ }^{[14]}$ ENREF 3 


\section{Supporting Information References:}

[1] S. N. Lou, N. Yap, J. Scott, R. Amal, Y. H. Ng, Sci. Rep. 2014, 4, 7428.

[2] M. M. Y. A. Alsaif, K. Latham, M. R. Field, D. D. Yao, N. V. Medehkar, G. A. Beane, R. B. Kaner, S. P. Russo, J. Z. Ou, K. Kalantar-zadeh, Adv. Mater. 2014, 26, 3931.

[3] A. S. R. Chesman, J. van Embden, N. W. Duffy, N. A. S. Webster, J. J. Jasieniak, Cryst. Growth Des. 2013, 13, 1712.

[4] J. Z. Ou, J. L. Carnpbell, D. Yao, W. Wlodarski, K. Kalantar-zadeh, J. Phys. Chem. C 2011, 115, 10757.

[5] D. Xiang, C. Han, J. Zhang, W. Chen, Sci. Rep. 2014, 4, 4891.

[6] K. Lee, M. S. Shur, T. J. Drummond, H. Morkoç, J. Appl. Phys. 1983, 54, 6432.

[7] J. B. Goodenough, A. Hamnett, O. Madelung, G. Huber, F. Hullinger, S. K. Ramasesha, H. Werheit, Physics of Non-Tetrahedrally Bonded Binary Compounds III / Physik Der Nicht-Tetraedrisch Gebundenen Binären Verbindungen III, Vol. 41D, Springer, Berlin, Germany 1984.

[8] S. Balendhran, J. Deng, J. Z. Ou, S. Walia, J. Scott, J. Tang, K. L. Wang, M. R. Field, S. Russo, S. Zhuiykov, M. S. Strano, N. Medhekar, S. Sriram, M. Bhaskaran, K. Kalantarzadeh, Adv. Mater. 2013, 25, 109.

[9] S. Gokden, Physica E Low Dimens Syst Nanostruct 2004, 23, 19.

[10] Z. L. Pei, C. Sun, M. H. Tan, J. Q. Xiao, D. H. Guan, R. F. Huang, L. S. Wen, J. Appl. Phys. 2001, 90, 3432.

[11] L. Mai, F. Yang, Y. Zhao, X. Xu, L. Xu, B. Hu, Y. Luo, H. Liu, Mater. Today 2011, $14,346$.

[12] B. L. Gelmont, M. Shur, M. Stroscio, J. Appl. Phys. 1995, 77, 657. 
[13] M. M. Y. A. Alsaif, M. R. Field, B. J. Murdoch, T. Daeneke, K. Latham, A. F. Chrimes, A. S. Zoolfakar, S. P. Russo, J. Z. Ou, K. Kalantar-zadeh, Nanoscale 2014, 6, 12780.

[14] V. Lemos, F. Camargo, J. Raman Spectrosc. 1990, 21, 123. 